\title{
Atmospheric ions and nucleation: a review of observations
}

\author{
A. Hirsikko ${ }^{1}$, T. Nieminen ${ }^{1}$, S. Gagné ${ }^{1,2}$, K. Lehtipalo ${ }^{1}$, H. E. Manninen ${ }^{1}$, M. Ehn ${ }^{1}$, U. Hõrrak ${ }^{3}$, V.-M. Kerminen ${ }^{1,4}$, \\ L. Lakso ${ }^{1,4,5}$, P. H. McMurry ${ }^{6}$, A. Mirme ${ }^{3}$, S. Mirme ${ }^{3}$, T. Petäjä ${ }^{1}$, H. Tammet ${ }^{3}$, V. Vakkari $^{1}$, M. Vana ${ }^{1,3}$, and \\ M. Kulmala ${ }^{1}$ \\ ${ }^{1}$ Department of Physics, P.O. Box 64, 00014 University of Helsinki, Finland \\ ${ }^{2}$ Helsinki Institute of Physics and University of Helsinki, Department of Physics, P.O. Box 64, \\ 00014 University of Helsinki, Finland \\ ${ }^{3}$ Institute of Physics, University of Tartu, 18 Ülikooli Str., 50090 Tartu, Estonia \\ ${ }^{4}$ Finnish Meteorological Institute, Research and Development, P.O. Box 503, 00101 Helsinki, Finland \\ ${ }^{5}$ School of Physical and Chemical Sciences, North-West University, Potchestroom, Republic of South Africa \\ ${ }^{6}$ Particle Technology Laboratory, University of Minnesota, Minneapolis, Minnesota, USA
}

Received: 20 September 2010 - Published in Atmos. Chem. Phys. Discuss.: 19 October 2010

Revised: 14 January 2011 - Accepted: 16 January 2011 - Published: 26 January 2011

\begin{abstract}
This review is based on ca. 260 publications, 93 of which included data on the temporal and spatial variation of the concentration of small ions $(<1.6 \mathrm{~nm}$ in diameter) especially in the lower troposphere, chemical composition, or formation and growth rates of sub-3 nm ions. This information was collected on tables and figures. The small ions exist all the time in the atmosphere, and the average concentrations of positive and negative small ions are typically $200-2500 \mathrm{~cm}^{-3}$. However, concentrations up to $5000 \mathrm{~cm}^{-3}$ have been observed. The results are in agreement with observations of ion production rates in the atmosphere. We also summarised observations on the conversion of small ions to intermediate ions, which can act as embryos for new atmospheric aerosol particles. Those observations include the formation rates $\left(J_{2}\right.$ [ion] $)$ of 2-nm intermediate ions, growth rates (GR[ion]) of sub-3 $\mathrm{nm}$ ions, and information on the chemical composition of the ions. Unfortunately, there were only a few studies which presented $J_{2}$ [ion] and GR[ion]. Based on the publications, the formation rates of 2-nm ions were $0-1.1 \mathrm{~cm}^{-3} \mathrm{~s}^{-1}$, while the total 2-nm particle formation rates varied between 0.001 and $60 \mathrm{~cm}^{-3} \mathrm{~s}^{-1}$. Due to small changes in $J_{2}$ [ion], the relative importance of ions in 2-nm particle formation was determined by the large changes in $J_{2}$ [tot], and, accordingly the contribution of ions increased with decreasing $J_{2}[$ tot]. Furthermore, small ions were observed to activate for growth earlier than neutral nanometer-sized particles and at lower saturation ratio of condensing vapours.
\end{abstract}

Correspondence to: A. Hirsikko (anne.hirsikko@helsinki.fi)

\section{Introduction}

Atmospheric aerosol particles influence the Earth's climate system (e.g. Myhre, 2009; Quaas et al., 2009), impair visibility (Hand and Malm, 2007), and have adverse effects on human health (e.g. Russell and Brunekreef, 2009). These effects of atmospheric aerosol particles are dependent on their number concentration, size, chemical composition, and to some extent, their charge.

Atmospheric ions, or air ions, are carriers of electrical current in atmospheric air. Electrical conductivity of air was discovered by Richmann in 1744 (Richmann, 1751, 1956) and rediscovered by Coulomb (1785). The ionisation of neutral molecules was proposed as an explanation for conductivity by Faraday (1834) who wrote: “....Finally, I require a term to express those bodies which can pass to the electrodes... I shall call them ions". The quantitative research of laboratory-generated air ions begun under supervision of Thomson in the Cavendish Laboratory (Thomson, 1903), using the time-of-flight method, proposed by Rutherford (1897). The aspiration method was proposed simultaneously by Zeleny (1898) and McClelland (1898). Natural atmospheric ions were not considered in these early studies. The pioneers in the atmospheric ion studies were Elster and Geitel (1899), Ebert (1901) and Langevin (1905). The early research of air ions is well summarised by Israël (1970) and Flagan (1998). Formerly, research on air ions mainly focused on atmospheric electricity, however, the data have also been to monitor air quality and radioactivity (e.g. Misaki et al., 1972a,b, 1975; Tuomi, 1989; Israelsson and Knudsen, 1986; Retalis and Pitta, 1989). During the last decades, also atmospheric aerosol scientists have aknowledged the importance of air ions.

Published by Copernicus Publications on behalf of the European Geosciences Union. 
Air ions larger than $1.6 \mathrm{~nm}$ in mass diameter are defined as charged aerosol particles according to their physical nature (Tammet, 1995), whereas smaller air ions are charged molecules or molecular clusters (e.g. Ehn et al., 2010; Junninen et al., 2010). The atmospheric electricity measurement community divides the air ion population into small, intermediate and large ions. These ion modes were already observed in the early decades of electrical aerosol measurements (Elster and Geitel, 1899; Langevin, 1905; Pollock, 1915; Israël, 1970; Flagan, 1998). The same classification scheme will be used in this paper. However, in some studies the term "cluster ion" has been used to describe the whole small ion population (e.g. Hõrrak et al., 2000; Hirsikko et al., 2005). The air ion classification was further developed based on long term measurements at Tahkuse Observatory, Estonia, and the boundary between the intermediate and large ions was found to be at $7.4 \mathrm{~nm}$ in mass diameter (Hõrrak et al., 2000, 2003).

The primary sources of air ions are radon decay, gamma radiation, and cosmic radiation (Israël, 1970; Bazilevskaya et al., 2008). Other ionisation mechanisms are negligible sources of air ions in the lower atmosphere (Harrison and Tammet, 2008). Other known sources for small ions are traffic, corona dischargers (e.g. power lines, and point dischargers in the case of enhanced atmospheric electric field, like thunder storms) and splashing water (e.g. Chalmers, 1952; Eisele 1989a,b; Haverkamp et al., 2004; Tammet et al., 2009). Primary ions (singly charged positive ions and free electrons) form via ionisation of air molecules, and they become small ions in less than a second. During their life time of ca. $100 \mathrm{~s}$, small ions undergo a series of ion-molecule reactions and continuously change their chemical identity. Thus, the chemical composition of small ions depends on the age of the ions and on the trace gas concentration in the air (Mohnen, 1977; Keesee and Castleman, 1985; Viggiano, 1993; Luts and Parts, 2002; Parts and Luts, 2004). Air ions are redistributed into particles of different sizes by coagulation with pre-existing aerosol particles and by their growth to larger sizes, or they can be lost by ion-ion recombination and dry deposition (Hidy, 1984; Hoppel and Frick, 1990; Seinfeld and Pandis, 1998; Tammet et al., 2006).

Small ions exist practically all the time and throughout the troposphere, as evidenced by a large number of observations made both close to the Earth's surface and at various altitudes up to several kilometres (e.g. Arnold et al., 1978; Eichkorn et al. 2002; Dhanorkar and Kamra, 1993a; Vartiainen et al., 2007; Hirsikko et al., 2005, 2007c; Virkkula et al., 2007; Vana et al., 2008, Suni et al., 2008, Laakso et al., 2008; Venzac et al., 2007, 2008; Mirme et al., 2010). In contrast, intermediate ions are usually detected only during periods of new-particle formation, snowfall or falling water droplets, or at high-wind speed conditions (snowstorm) in winter (e.g. Hõrrak et al., 1998b; Hirsikko et al., 2005, 2007a; Virkkula et al, 2007; Laakso et al., 2007b; Tammet et al., 2009; Manninen et al., 2010). When new aerosol particles are formed by nucleation, intermediate ions are produced by ion-mediated pathways (e.g. Froyd and Lovejoy, 2003a,b; Lovejoy et al., 2004; Yu and Turco, 2000, 2008; Yu, 2010; Yu et al., 2010) or via the attachment of small ions to newly-formed neutral particles (e.g. Iida et al., 2006).

Several review articles that discuss various aspects of air ions have recently been published. These reviews show that while atmospheric new-particle formation is a frequent phenomenon taking place almost all over the world (Kulmala et al., 2004a; Smirnov, 2006; Kulmala and Kerminen, 2008; Kerminen et al., 2010), the role of ions in this process is not well quantified (e.g. Kulmala and Tammet, 2007; Enghoff and Svensmark, 2008; Arnold, 2008; Laakso et al., 2007a; Yu and Turco, 2008; Manninen et al., 2010). In a global perspective, ion-aerosol-cloud interactions have potential climatic implications (Harrison and Carslaw, 2003; Kazil et al., 2008).

Despite the increasingly active research on air ions during the last decade, no comparative studies on the evolution of small ion concentrations in different environments have been published to date. The main focus of this review is to provide a comprehensive overview of the spatial and diurnal variations of the naturally created small ion concentrations in the lower troposphere, along with the dependence of these concentrations on the ion sources and sinks. Another focus is to look at the connection between air ions and atmospheric newparticle formation. We begin our analysis by introducing theoretical considerations on the mobility-diameter conversion and the balance equation for small ion population (Sect. 2), we continue with the relevant measurement devices (Sect. 3), small ion observations (Sect. 4) and connections between ions and atmospheric new-particle formation (Sect. 5), and complete by presenting some concluding remarks (Sect. 6).

\section{Air ions}

In this section we discuss the conversion of mobility to diameter, since typically mobility distributions are measured but size distributions are presented (Sect. 2.1). In Sect. 2.2 we discuss the balance equation for small ions, and in Sect. 2.3, the connection between air ions and conductivity is discussed.

\subsection{Physical parameters of air ions}

The physical parameters of an air ion are its mass $m$, diameter $d$, density of ionic matter $\rho$, electric charge $q_{e}$, and electrical mobility $Z$. The electric charge of small ions in the atmosphere is always one elementary charge $q_{e}=e$ (e.g. Hinds, 1999 ) and the diffusion coefficient $D$ is related to the mobility according to the Einstein relation

$D=\frac{k T Z}{q_{e}}$

where $k$ is the Boltzmann constant and $T$ is temperature in Kelvin. The mass of an ion can be unambiguously measured 


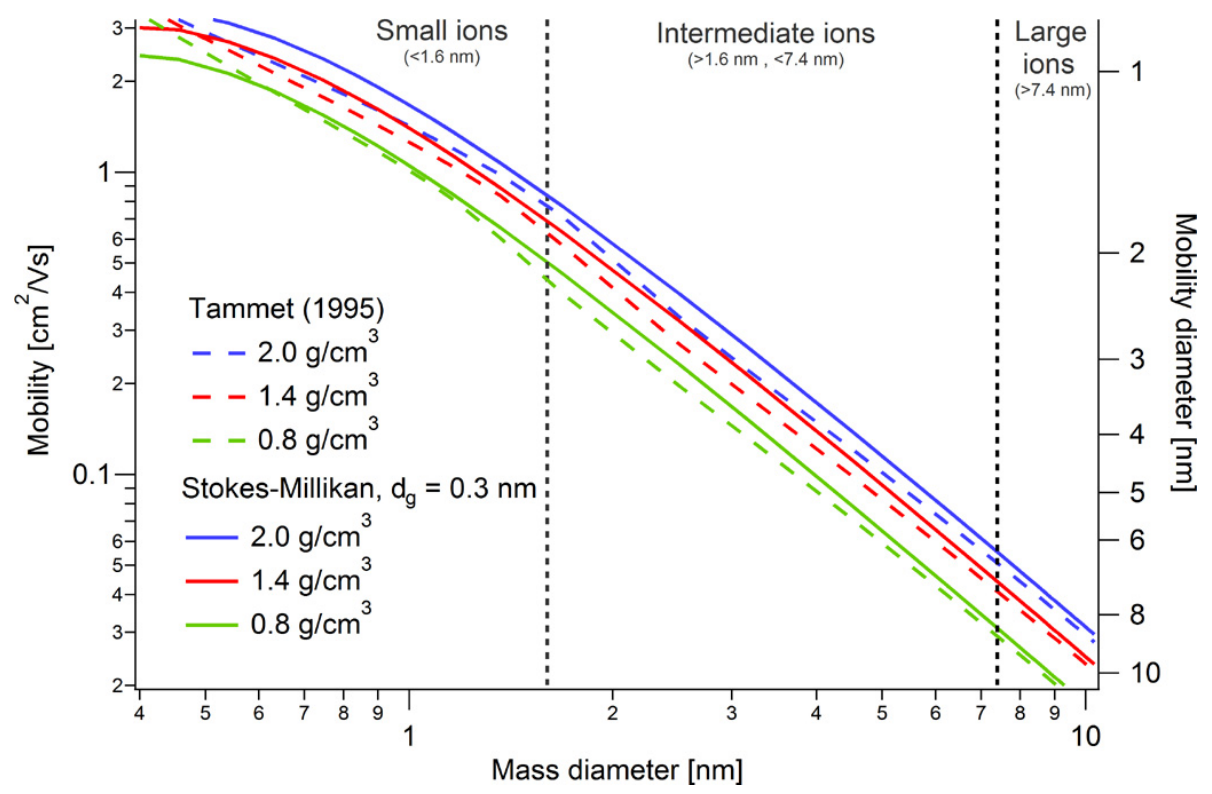

Fig. 1. Mobility versus mass- and mobility diameter calculated according to Tammet (1995) and modified Stokes-Millikan (Ku and de la Mora, 2009) using three different densities.

by means of a mass spectrometer and the electrical mobility can be measured by means of a mobility analyser. Thus only two parameters, diameter $(d)$ and density $(\rho)$ of particles, are not unambiguously defined.

The term "mobility size" is often used in aerosol research. Unfortunately, this term is ambiguous, because different authors use different models of size-mobility relation (see Mäkelä et al., 1996; Li and Wang, 2003; Ehn et al., 2011). The traditional macroscopic model that assumes a particle as a sphere with an exactly determined geometric surface is not adequate in the nanometer size range. In atomic physics, the microscopic particles are characterised by the interaction potential and collision cross-sections. The concept of the surface is sometimes not applicable and particles are characterised by continuous coordinate functions. To correct the situation, Mason (1984) proposed the mass diameter

$d_{m}=\sqrt[3]{\frac{6 m}{\pi \rho}}$

as a size parameter of ions. The concept of size of an aerosol particle was analysed by Tammet (1995) and the mass diameter was recommended as a preferable universal model parameter for ions or aerosol particles.

Tammet (1995) derived a semi-empirical size-mobility model, which approaches the Chapman-Enskog equation when the particle size decreases, and the Millikan equation when the particle size increases (Chapman and Cowling, 1970; Millikan, 1923). The concept of size was preserved using the ( $\infty-4)$ potential from the kinetic theory and the transfer between the microscopic and macroscopic limits was accomplished by accounting for the dependence of the law of the reflection of gas molecules on the particle size and considering of the collision distance as a function of the interaction energy. The result was formulated as a computing algorithm given by Tammet (1995) and later corrected by Tammet (1998). Another sophisticated model (Li and Wang, 2003) is based mostly on theoretical calculations.

Unfortunately, the sophisticated models are in some respects inconvenient in the practice of air ion and aerosol measurements. If the size range below $1.5 \mathrm{~nm}$ is not important, the models can be essentially simplified. In this case the main difference between the Tammet model and the classic StokesMillikan model is the consideration of the gas molecule size that is approximately $0.3 \mathrm{~nm}$. In Fig. 1 we present a simple relationship between mass diameter, mobility and mobility diameter. The solid lines show the conversion between mass diameter and mobility according to a modified StokesMillikan formulation (Ku and de la Mora, 2009), and the dashed lines a similar conversion based on the formulation by Tammet (1995).

$\mathrm{Ku}$ and de la Mora (2009) studied the size to mobility conversion in laboratory with different liquid and solid particle samples. They found that the original Stokes-Millikan law, as presented by Friedlander (1977) agrees with the observation down to $d=1.3 \mathrm{~nm}$ for spherical particles if $d_{\text {Millikan }}=d_{m}+d_{g}$, where the gas molecule diameter $d_{g}=$ $0.3 \mathrm{~nm}$. These results were confirmed by observation in natural air in Hyytiälä, Finland (Ehn et al., 2011). Larriba et al. (2011) found that the $0.3 \mathrm{~nm}$ correction was accurate within $3.84 \%$ and $14.3 \%$ for particles with volume diameters of $1.21 \mathrm{~nm}$ and $0.68 \mathrm{~nm}$, respectively. 
The small negative ions typically have a larger mobility than the positive ones (Hõrrak et al., 1994, 2000; Harrison and Aplin, 2007). Air chemistry, temperature (Salm et al., 1992) and pressure as well as sink due to aerosol particles affect the mean mobilities of small ions. Thus different values of the mean mobility of small ions in both polarities have been reported in the literature (e.g. Eichmeier and Braun, 1972; Suzuki et al., 1982; Hõrrak et al., 1994).

\subsection{The formation and loss of small ions}

The concentration of air ions changes in time due to different formation and loss processes according to the simplified balance equations:

$\frac{d n}{d t}=q-\beta_{\mathrm{eff}} Z_{\mathrm{tot}} n-\alpha n^{2}$

$$
\text { or }
$$

$$
\frac{d n}{d t}=q-\operatorname{Coag} S \cdot n-\alpha n^{2} .
$$

Equation (3) is from Israël (1970) and Eq. (4) is a modified form of that equation from Kulmala et al. (2001). New air ions are formed via air molecule ionisation (the first terms on right hand side). At the same time they are lost by the coagulation with the pre-existing aerosol with a total concentration of $Z_{\text {tot }}$ (the second term in Eq. 3). In Eq. (4), coagulation is described by the coagulation sink coefficient Coag $S$ (Kulmala et al., 2001), which is obtained by integrating over the particle size distribution. In addition ions are lost via ion-ion recombination (the third terms on right). The coefficient $\alpha$ is the ion-ion recombination coefficient, and $\beta_{\text {eff }}$ is the efficient ion-aerosol attachment coefficient.

Equations (3) and (4) are sufficient for the following discussion in this review. However, more detailed analysis requires considerations of: (1) additional sinks, (growth, deposition due to electric fields, and dry deposition, Tammet et al., 2006; Hõrrak et al., 2008), (2) local sources (corona discharger, traffic), and (3) errors caused by assuming equal concentrations of small positive and negative ions and symmetrical charging of aerosol particles.

Based on the balance Eqs. (3) and (4), we can calculate the maximum limit for small ion concentration if we assume a steady state situation $\left(\frac{d n}{d t}=0\right)$ and exclude the effect of background aerosol, thus ending up to the equation $q=\alpha n^{2}$. The coefficient $\alpha$ is about $1.6 \times 10^{-6} \mathrm{~cm}^{3} \mathrm{~s}^{-1}$ under typical atmospheric conditions (Israel, 1970; Hoppel, 1985; Hoppel and Frick, 1986). With these assumptions, ion production rates $q=2,10$ and $100 \mathrm{~cm}^{-3} \mathrm{~s}^{-1}$ lead to concentrations of positive and negative small ions of 1100,2500 and $7900 \mathrm{~cm}^{-3}$, respectively.

\subsection{Relation between small ions and air conductivity}

As discussed in the introduction, air conductivity was discovered already in the 18th century (Richmann, 1751, 1956;
Coulomb, 1785). Small ions make most of the air conductivity, however, larger ions have been observed to contribute as well (e.g. Dhanorkar and Kamra, 1992, 1993b). Hõrrak (2001) carried out and analysed long-term air ion measurements (containing 8615 hourly average air ion mobility distributions) at Tahkuse, Estonia, to obtain relative contribution of small ions to air conductivity. According to Horrak (2001), the relative standard deviation of the small air ion mobility variation was about $6 \%$ while the relative standard deviation of the small ion concentration variation was about $36 \%$, and the correlation between the conductivity and the small air ion concentration was 98-99\%. The small ions appeared to be responsible for $96.3 \%$ of the full air ion conductivity. Thus, the small air ion concentrations $n_{+}$and $n_{-}$ can be estimated according to measured air polar conductivities $\lambda_{+}$and $\lambda_{-}$according to equations

$n_{+} \approx 0.96 \lambda_{+} /\left(Z_{+} e\right)$

and

$n_{-} \approx 0.96 \lambda_{-} /\left(Z_{-} e\right)$

where $Z$ is the mean electric mobility and $e$ is the elementary charge. The mean electric mobilities of small ions at Tahkuse were $Z_{+}=1.36 \mathrm{~cm}^{2} \mathrm{~V}^{-1} \mathrm{~s}^{-1}$ and $Z_{-}=1.53 \mathrm{~cm}^{2} \mathrm{~V}^{-1} \mathrm{~s}^{-1} \mathrm{ac}-$ cording to Hõrrak (2001). This relation is essential because the available datasets of atmospheric air conductivity supersede the datasets of air ion concentration measurements. For example, the largest composite open-access dataset ATMEL2007A (Tammet, 2009) consists of 1, 615, 159 hourly mean values of measured polar conductivities, while the number of direct measurements of small ion concentrations in the dataset is 305,605 .

\section{Instrumentation used in air ion measurements}

We begin this section with the integral aspiration counters (Sect. 3.1). Then we continue by introducing the singlechannel differential aspiration spectrometers (Sect. 3.2), multi-channel aspiration spectrometers (Sect. 3.3), special configurations of aspiration condensers (Sect. 3.4) and drift tube mobility analysers (Sect. 3.5). Finally, we finish the section with the applications of mass-spectrometry to studies of the chemical properties of air ions (Sect. 3.6) and a short summary of the instrumentation (Sect. 3.7).

\subsection{Integral aspiration counter}

Ventilated coaxial condensers were introduced in the first studies of air ions and a theory for the functioning of such instruments was established by Riecke (1903). However, the simplest aspiration condenser is often called a Gerdien condenser because it became a popular tool for atmospheric air conductivity and air ion concentration measurements after publications by Gerdien $(1903,1905)$. 
A steady voltage $V$ is applied between the two coaxial electrodes of an integral aspiration condenser, and the space between the electrodes is ventilated with an air flow $Q$. The electric current of deposited air ions $I$ is measured by means of an electrometer. As shown by Riecke (1903), the air ion current at a low voltage is

$I=\frac{C V \lambda}{\varepsilon}$,

where $C$ is the active capacitance between the electrodes, $\lambda$ is the electric conductivity and $\varepsilon$ is the absolute permittivity of the air, which is close to the electric constant. The electric current caused by air ions saturates for voltages that exceed a critical value. This saturated current is

$I=n e Q$,

where $n$ is the concentration of ions and $e$ is the elementary charge. The theory above allows using the integral aspiration condenser at a low driving voltage for measuring the air conductivity, and at a high driving voltage for measuring of the ion concentration. A detailed discussion of aspiration condensers can be found in the books by Israël (1970) and Tammet (1970).

The current of mono-mobile ions in an axi-symmetric integral aspiration condenser saturates abruptly according to Eq. (7), and reaches saturated current calculated according to Eq. (8). The transition criterion is

$Z=Z_{o}=\frac{Q \varepsilon}{C V}$

where $Z_{o}$ is called limiting mobility. The characteristic function of an integral aspiration condenser (volt-ampere characteristic) is piecewise linear in the case of the mono-mobile ions and increases smoothly and systematically with increasing voltage in the case of a continuous mobility distribution. The distribution of air ions with respect to mobility is related to the second derivative of this volt-ampere characteristic curve. The air ion concentration is fluctuating in the atmospheric ground layer due to turbulence and the atmospheric electric field. The fluctuations in the measured air ion concentration complicate experimental determination of the volt-ampere characteristic curve and, therefore, amplify the uncertainties when estimating the derivatives from that volt-ampere characteristic. Thus an instrument based on an integral aspiration condenser has a very low mobility resolution allowing the distinguishing of only a few groups of air ions in a wide mobility range. The integral aspiration condensers are mostly used as integral air ion counters that are not capable for mobility spectrometry.

Israël's portable ion counter (Israël, 1929) contributed significantly to our understanding of air ions (Israël, 1931, 1970). This integral aspiration counter allowed measurements over a wide range of mobility, including large ions. The instrument consists of two identical aspiration condensers that can be used for simultaneous measurements of positive and negative air ions, or connected in series for measurements of ions of one polarity. The design of many further instruments was based on Israël's counter.

Several integral air ion counters were developed and used for extensive measurements in Tartu, Estonia (Matisen et al., 1992). The counter by Reinet (1956) had separate aspiration condensers for small and large ions. It was used for long term measurements of several air ion mobility classes (Reinet, 1958). During these measurements, bursts of intermediate ions were recorded, but the nature of the bursts was not understood. The counter was upgraded by Prüller and Saks (1970), who added automatic data recorders replacing manual data collection. Thereafter portable integral counters with an external collector electrode were developed (Tammet, 1970; Matisen et al., 1992) and more than 100 of these instruments were manufactured for various scientific institutions, mostly in Former Soviet Union. These ion counters were also used in measurements at Vilsandi Island in Estonia during different expeditions. The measurements in July-September 1984 provided with an average concentrations of positive and negative small ions (limiting mobility $0.32 \mathrm{~cm}^{2} \mathrm{~V}^{-1} \mathrm{~s}^{-1}$ ) of 261 and $173 \mathrm{~cm}^{-3}$, respectively Hõrrak (1987).

Dhanorkar and Kamra (1992, 1993b) operated three Gerdien counters in parallel with a common fan for air flow, each set to measure a different mobility range, i.e. small ions $\left(\geq 0.75 \mathrm{~cm}^{2} \mathrm{~V}^{-1} \mathrm{~s}^{-1}\right)$, intermediate ions $\left(\geq 2 \times 10^{-2} \mathrm{~cm}^{2} \mathrm{~V}^{-1} \mathrm{~s}^{-1}\right)$ and large ions $\left(\geq 2.3 \times 10^{-4} \mathrm{~cm}^{2} \mathrm{~V}^{-1} \mathrm{~s}^{-1}\right)$. This Gerdien counter setup was further modified by Dhanorkar and Kamra (1993a) to allow for measurements at a set of voltages for each condenser. This modified instrument enables measurements of mobility distributions in the ranges of $0.24-3.37 \mathrm{~cm}^{2} \mathrm{~V}^{-1} \mathrm{~s}^{-1}, \quad 0.0243-0.147 \mathrm{~cm}^{2} \mathrm{~V}^{-1} \mathrm{~s}^{-1}$ and $6.91 \times 10^{-4}-0.0132 \mathrm{~cm}^{2} \mathrm{~V}^{-1} \mathrm{~s}^{-1}$. Ion concentration measurements by Gerdien counters have also been conducted in the Antarctica (Siingh et al., 2007; Kamra et al., 2009) and on-board a ship in the Arabian Sea (Siingh et al., 2005; Pawar et al., 2005). In the Gerdien counter setup by Pawar et al. (2005) and Kamra et al. (2009) the mobility ranges for small, intermediate and large ions were $<1.45 \mathrm{~nm}\left(>0.77 \mathrm{~cm}^{2} \mathrm{~V}^{-1} \mathrm{~s}^{-1}\right)$, $1.45-12.68 \mathrm{~nm}\left(1.21 \times 10^{-2}-0.77 \mathrm{~cm}^{2} \mathrm{~V}^{-1} \mathrm{~s}^{-1}\right)$ and 12.68 $130 \mathrm{~nm} \quad\left(0.97 \times 10^{-4}-1.21 \times 10^{-2} \mathrm{~cm}^{2} \mathrm{~V}^{-1} \mathrm{~s}^{-1}\right)$, respectively. Duplissy et al. (2010) also used a Gerdien counter during a Cosmics Leaving Outdoor Droplets (CLOUD) experiment in CERN.

Aplin and Harrison (2000) used a Gerdien counter, which was modified to be able to vary the electric field between the cylinders as the air flowed through the annular gap between them. An electrometer measured the current delivered by the ions as they deposited on the central electrode. Further development by Harrison and Aplin (2007) is the Programmable Ion Mobility Spectrometer (PIMS). A bias voltage is applied to the outer cylinder and the electric current of ions deposited 
on the inner cylinder electrode is recorded. The PIMS measures small mobility ranges at a time by alternating the voltage step by step from positive to negative. The whole measurement cycle took $30 \mathrm{~min}$.

Ling et al. (2010) used two modern portable Alphalab air ion counters, one for positive and the other for small negative ions when measuring at 32 different urban sites in an Australian city. Unfortunately, name of this city was not mentioned. The limiting mobility of the ion counters was $0.5 \mathrm{~cm}^{2} \mathrm{~V}^{-1} \mathrm{~s}^{-1}$.

\subsection{Single-channel differential aspiration spectrometers}

In single-channel differential aspiration spectrometers, ions are collected onto a collector ring or plate. If this ring is narrow, the distribution of air ions according to the mobility is related to the first derivative of the volt-ampere curve. These ion spectrometers are called first order differential spectrometers. Thus the effect of fluctuations in the ion concentration is partially suppressed compared to the integral condenser. Also, this instrument includes separate inlets for ions and sheath air. The sheath air is deionised by means of a filter. If both the collector electrode and the inlet air flow are divided, we get a differential aspiration condenser of the second order, where the operation of calculating the derivatives is replaced by a physical differentiation (Sect. 3.3).

In the first aspiration condensers the air ions were collected onto an electrode inside of the condenser and the electric current caused by ions was measured by a single electrometer connected to the electrode. This electrode was exposed to a driving electric field, and the smallest changes in the electric field caused large error in the electrometer output signal. Thus, Hewitt (1957) replaced the divided electrode in the differential aspiration condenser with a divided output air flow, where larger amount of excess air was sucked away and only a small amount of classified air was passed to a detector. This kind of first order differential aspiration condenser is commonly called a DMA (Differential Mobility Analyzer). The amount of classified air ions is measured by means of a Faraday cup electrometer or a condensation particle counter (CPC), which can be used in case of large ions.

The DMA was initially developed as a tool to produce particles of known size, composition and concentration for calibrating aerosol instruments (Liu and Pui, 1974). Knutson and Whitby (1975) derived a theory that accurately describes the mobility distribution of non-diffusing particles classified by the DMA. Stolzenburg (1988) later extended the theory to account for the effects of diffusion (Stolzenburg and McMurry, 2008).

Laakso et al. (2007a) and Gagné et al. $(2008,2010)$ used an Ion Differential Mobility Particle Sizer (Ion-DMPS) for detecting the charging state of aerosol particle populations. The charging state describes whether the particles are in charge equilibrium or if they are over- or under-charged, and it is one way to study the role of ions in particle formation
(Vana et al., 2006; Iida et al., 2006; Laakso et al., 2007a; Kerminen et al., 2007; Gagné et al., 2008). The Ion-DMPS is a DMPS completed with a bipolar charger which can be switched on and off, and a DMA that can measure both polarities in turns to get four different kinds of particle size distributions: (1) naturally charged positive particles, (2) naturally charged negative particles, (3) charge equilibrium negative particles, and (4) charge equilibrium positive particles. This setup avoids systematic errors when estimating the charging state of aerosol particles compared to the more commonly used setups consisting of two separate instruments to measure air ion and aerosol particle concentrations in the same size range due to differences in instruments or inlets.

In principle, CPCs are more sensitive detectors of air ions than the aerosol electrometers. The detection limits of CPCs were extended down to $3 \mathrm{~nm}$ by Stolzenburg and McMurry in 1991. Only recent advances in the developments of CPCs allow the use of CPC-equipped DMA-s for measuring the air ions of diameter down to $1 \mathrm{~nm}$ (e.g. Sgro and de la Mora, 2004; Kulmala et al., 2007; Sipilä et al., 2008, 2009; Iida et al., 2009; Vanhanen et al., 2011).

Based on the Nolan's subdivided condenser (Nolan and Sachy, 1927), Misaki (1950) introduced a method using the first order differential ion probes to measure small and intermediate ion mobility distributions. Both instruments consist of two coaxial cylindrical electrodes separated by annular gaps. The inner electrode is divided into four sections: the first and the fourth are grounded, while the second and the third sections are the measuring electrodes. The outer cylinder is connected to a voltage supply. The voltage varies, and is divided into 20 or 30 steps. Later, Misaki (1961a,b) used this setup with mobility ranges of $0.2-3.0 \mathrm{~cm}^{2} \mathrm{~V}^{-1} \mathrm{~s}^{-1}$ and $0.005-0.2 \mathrm{~cm}^{2} \mathrm{~V}^{-1} \mathrm{~s}^{-1}$ at Tokyo and Karuiwaza.

The Balanced Scanning Mobility Analyser BSMA (Tammet, 2006) is a single-channel differential aspiration condenser that includes two parallel aspiration condensers, connected as a balanced capacitance bridge. This eliminates the electro statically induced current and makes possible to continuously scan through the mobility range of 0.032$3.2 \mathrm{~cm}^{2} \mathrm{~V}^{-1} \mathrm{~s}^{-1}$, which approximately corresponds to ion mass diameters of $0.4-7.5 \mathrm{~nm}$. An extra high flow rate of 2400 LPM may cause difficulties in installing the instrument but decreases the losses of ions in the inlets significantly compared to instruments operating at lower flow rates. The BSMA has been used for measurements in Hyytiälä, Finland (Kulmala et al., 2005), since spring 2003 (Hirsikko et al., 2005), and in San Pietro Capofiume, Italy, for over six months in 2008 (Manninen et al., 2010), as well as for studies of rainfall-induced ions in Tartu (Tammet et al., 2009). The BSMA enables calibration according to the geometric dimensions, voltage and flow rate, and it was used as reference in calibration of different mobility spectrometers (Asmi et al., 2009) and the mass-spectrometric instrument APi-TOF (Junninen et al., 2010). 


\subsection{Multichannel aspiration spectrometers}

An aspiration condenser with a divided collector electrode was proposed already in the early stage of air ion research (Zeleny, 1900). In a multichannel aspiration condenser the collector electrode is divided into many rings and the collected ions are measured simultaneously. As a result, the time required to obtain whole spectrum is shorter compared to when the mobility range is scanned, which is necessary in single-channel instruments to obtain the air ion mobility distribution. The multichannel instruments have many advantages: (1) the data are collected simultaneously with several electrometers and the full distribution is measured as fast as the signal from a single channel becomes available, (2) additionally, simultaneous measurements avoid errors associated with fluctuations of air ion concentrations. The main factor limiting the usage of multichannel instruments is the complicated construction and calibration, causing a high price and complex maintenance.

A second order differential aspiration condenser was first designed by Erikson (1921) for use in laboratory experiments. Yunker (1940) developed the first successful multichannel air ion spectrometer. The air ion mobility distribution measured by Yunker is in a good agreement with contemporary knowledge about the air ions. Yunker (1940) measured the mobility-spectrum of atmospheric ions in the range of mobilities between $10^{-3}$ and $2.0 \mathrm{~cm}^{2} \mathrm{~s}^{-1} \mathrm{~V}^{-1}$ using a divided-electrode air-blast method. A continuous recording method was employed and the entire spectrum lasted about one hour. The spectrum shows the ordinary small ions, and then a practically continuous distribution out to the lowest mobility measured. However, it was not practical to use multichannel methods for long term measurements before automated data acquisition techniques were developed.

In Tartu, Estonia, work was begun in the 1970s to develop multichannel aspiration spectrometers (Tammet et al., 1973). A long series of routine measurements by means of the multichannel analysers have been carried out at the Tahkuse station since 1988, although not continuously (e.g. Hõrrak et al., 1994, 2000). The Tahkuse instrument complex covers the mobility range of $0.00041-3.14 \mathrm{~cm}^{2} \mathrm{~V}^{-1} \mathrm{~s}^{-1}$ and includes three multichannel aspiration condensers: one for small ions, one for intermediate ions, and one for large ions. The details and analysis of the results are available in publications by Hõrrak et al. (1994, 1998b, 2000, 2003).

The most advanced multichannel air ion spectrometers developed at the University of Tartu in cooperation with SME AIREL, Estonia, are the Air Ion Spectrometer (AIS, Mirme et al., 2007) and its modifications (NAIS and airborne NAIS). The AIS consists of two parallel DMAs, one for positive ions and the otherone for negative ions. Each DMA consists of two concentric cylinders. Four different electric fields are introduced between the cylinders. Ions are classified according to their electrical mobility and the signals they produce are recorded by 21 insulated electrometers inside the outer cylin- der. Thus, the whole mobility spectrum is simultaneously measured for both polarities. The AIS operates at a 30 litres per minute (LPM) sample flow and 60 LPM sheath air flow per analyser. Mobility spectra for both polarities are typically obtained every five minutes in routine atmospheric measurements, but the integration time is user-adjustable. The AIS measures small ions and charged particles in the 0.0013$3.2 \mathrm{~cm}^{2} \mathrm{~V}^{-1} \mathrm{~s}^{-1}$ mobility range (mass diameter $0.5-40 \mathrm{~nm}$ ). Different size ranges are given in the literature due to the different conversion from mobility to size (Fig. 1).

The newest instruments based on the AIS are: (1) the Neutral cluster and Air Ion Spectrometer NAIS, which can also measure neutral particles beginning from ca. $2 \mathrm{~nm}$ (see e.g. Kulmala et al., 2007; Asmi et al., 2009, Manninen et al., 2009a), and (2) the airborne NAIS (Mirme et al., 2010), which is suitable for aircraft or different altitude measurements.

The BSMA, five AISes, and five NAISes were calibrated and inter-compared in two laboratory campaigns (Asmi et al., 2009; Gagné et al., 2011). Asmi et al. (2009) found that the ion spectrometers measure accurately when the aerosol was mono-disperse and the concentrations were high. However, when the ion/particle concentrations were decreased down to few hundred $\mathrm{cm}^{-3}$, measured concentrations were overestimated due to the background noise of signal. When measuring non-mono-disperse aerosol (as ambient air is), the data inversion of the AIS moves the ion spectrum towards smaller sizes in both polarities. Main conclusions by Gagné et al. (2011) were: (1) the ion spectrometers measured quite accuarately the mobility, however, (2) all ion spectrometers overestimated concentration at the smallest sizes, and (3) in the particle mode (neutral + charged) the NAISes overestimate the concentration in the whole size range. Altogether, when applying the spectrometers in parallel during both campaigns, different ion spectrometers showed consistent ion size distributions, although differences in ion concentrations were observed (Asmi et al., 2009; Gagné et al., 2011). These problems were explained as issued from the data processing algorithms (Asmi et al., 2009; Gagné et al., 2011).

During the CLOUD experiment in CERN, measurements of small ions with an AIS and self-made Gerdien counter (Franchin et al., 2010) in parallel were in good agreement for positive ions, whereas differences were observed for concentrations of small negative ions (Duplissy et al., 2010). The Gerdien counter was designed to operate with low flow rate, and had its limitations to operate when ion concentrations were low (Franchin et al., 2010). Recently, Ehn et al. (2011) compared the AIS and BSMA mobility spectra against mass spectra from an Atmospheric Pressure Interface Time-of-Flight Mass Spectrometer (APi-TOF, introduced in Sect. 3.6). The BSMA and the APi-TOF showed a good agreement, whereas the AIS and the APi-TOF showed some differences probably due to incorrect sizing and the asymmetry in transfer functions of the AIS. 
The AIS, NAIS and airborne NAIS have been used in many kinds of environments: on the sea shore in Mace Head, Ireland (Vana et al., 2008), on ships (Vana et al., 2007), on a train trip from Moscow to Vladivostok (Vartiainen et al., 2007), at high altitude mountains (Venzac et al., 2007, 2008), in a hot air balloon and onboard an air craft (Laakso et al., 2007b; Mirme et al., 2010) and in urban and rural regions that include e.g. Helsinki, Kuopio and in Hyytiälä, in Finland (Hirsikko et al., 2005, 2007b; Tiitta et al., 2007), at 12 locations in Europe durin the European Integrated project on Aerosol Cloud Climate and Air Quality Interactions campaign (EUCAARI, Manninen et al., 2010), South Africa (Laakso et al., 2008; Vakkari et al., 2010), Antarctica (Virkkula et al., 2007; Asmi et al., 2010), and Tumbarumba in Australia (Suni et al., 2008).

\subsection{Special configurations of aspiration condensers}

Most of the aspiration condensers have an axi-symmetric geometry. Alternative parallel plate geometries are not favourable in integral instruments but can be used in differential instruments, in which limiting of the width of the collector electrode allows to avoid edge distortions. Among the above mentioned instruments the plane geometry was used by Erikson (1921), Tammet $(2002,2003,2006)$ and in the DMA P5, which was recently commercialised by SEADM (Boecillo, Spain).

Hurd and Mullins (1962) proposed a radial geometry of the planar aspiration condenser, which turned out popular for laboratory research but only had a few applications for atmospheric research. The radial DMA by Zhang et al. (1995) was used to study atmospheric particle formation by Iida et al. (2008).

Loscertales (1998) showed that the diffusion broadening of the DMA transfer function can be suppressed when a component of the field is directed opposite to the flow. Tammet (1999) proposed the method of inclined grids, which puts the Loscertales' idea in practice, and pointed out that longitudinal electric fields had been used before by Zeleny (1898). The inclined grids method was used in the Inclined Grid Mobility Analyzer (IGMA, Tammet, 2002, 2003), which was used by Eisele et al. (2006) and Iida et al. (2006, 2008) for measuring ion and charged particle mobility/size distributions in atmospheric aerosol nucleation studies. The IGMA is single-channel differential aspiration condenser, and it classifies naturally charged air ions according to their mobility and measures the concentrations of mobility-classified ions with a highly sensitive electrometer (Faraday's method). The flow rate is high (3000 LPM) in order to improve the signal-to-noise ratios and reduce sampling losses. The mobility range of the IGMA $(0.05-$ $3.2 \mathrm{~cm}^{2} \mathrm{~V}^{-1} \mathrm{~s}^{-1}$ ) corresponds to a mass diameter range of $0.4-6.3 \mathrm{~nm}$. Although the inclined grid method was proposed to enhance the mobility resolution, in operation high mobility resolution was sacrificed so as to achieve high sensitivity, which is necessary for measuring small concentrations of intermediate ions.

Flagan (2004) proposed another instrument with an inclined electric field, called the Opposed Migration Aerosol Classifier (OMAC). The principle and configuration of the fields is the same as in the case of inclined grids, but the grids are replaced by porous electrodes. In contrast to the IGMA, where the primary goal was high sensitivity, the OMAC is designed to obtain a high mobility resolution at relatively low classifying voltages.

\subsection{Drift tube mobility analysers}

In the chemical applications of ion mobility spectrometry (IMS), ions are generated inside the instrument and measured a few milliseconds after they are generated. In this case the ion sampling problem is precluded and the ion concentrations may exceed the atmospheric concentrations by several orders of magnitude. An overview of the methods used in chemical applications can be found in the book by Eiceman and Karpas (2005). The dominating methods are the timeof-flight or drift tube method, where ions are generated by radioactive or corona source and drifted in a homogeneous electric field until the collector electrode. The time of the drift depends on the mobility of the ions and the mobility distribution can be derived when analysing the shape of the electric pulse generated by ions that reach the collector electrode.

The IMS technique is especially useful in laboratory studies to obtain information on ion processes. For example, Pedersen et al. (2008) used the IMS technique to characterise proton-bound acetate dimers. Using a drift tube, Nagato and Ogawa (1998) studied aging (up to $5 \mathrm{~s}$ ) and temperature dependence of artificially generated ion spectra in ambient laboratory air, and Nagato et al. (1999) studied the same effects in atmospheric conditions at Green Mountain Mesa. However, atmospheric spectra by the IMS is typically complex, and, thus, there are less attempts to use drift tubes to analyse atmospheric ions. Zvang and Komarov (1959) used a special drift tube to measure natural small ions in the atmosphere up to the height of $5 \mathrm{~km}$, but encountered difficulties due to the method. Myles et al. (2006) used the IMS technique to study ammonia concentrations in the atmosphere.

\subsection{Mass-spectrometry in air ion research}

Mass spectrometers are able to measure the mass-to-charge ratio of ions in a vacuum. Thus, the main problem in mass spectrometry of air ions is transferring the ions into the vacuum without high losses or perturbation of ion composition. As stated earlier, small air ions are typically singly charged, which means that we can convert the mass-to-charge ratio directly into ion mass. Identification of the masses of several atmospheric ions has been made by Eisele and his collaborators in a long series of papers beginning with 
Eisele (1983) and finishing with Eisele et al. (2006). The identification process has recently been continued by Junninen et al. (2010) at Helsinki, Finland, and Ehn et al. (2010) at Hyytiälä, Finland, by means of a high resolution timeof-flight mass spectrometer (Atmospheric Pressure Interface Time-of-Flight Mass Spectrometer, APi-TOF, manufactured by Tofwerk AG, Switzerland).

Another new tool is the Cluster Chemical Ionization Mass Spectrometer (Cluster CIMS) (Zhao et al., 2010), which detects sulphuric acid vapour and neutral molecular clusters formed by nucleation. As shown by Jiang et al. (2011a), the clusters measured by the Cluster CIMS overlap in size with the smallest nano condensation nuclei measured by the Diethylene Glycol Scanning Mobility Particle Sizer (DEG SMPS, Jiang et al., 2011b), and the measured concentrations were in reasonable agreement. The measurements with the Cluster CIMS provide valuable new information about the mechanism of neutral nucleation and growth.

\subsection{Summary of the instruments used in air ion studies}

The instrumentation used in air ion studies has evolved from single channel integral instruments to multichannel instruments which simultaneously measure the entire size range of ions. The most widely used instruments today are air ion spectrometers by Airel Ltd., Gerdien counters and DMAs connected to CPCs. The latest innovations have come in particle mass spectrometry, allowing high resolution mass measurements of ions, and the possibility to measure selected neutral clusters. With these new instruments, ions of diameters $\leq 1 \mathrm{~nm}$ can be measured.

\section{Measured air ion properties}

In this section, we discuss on the ion production rate via ionisation (4.1), concentration of small ions as a function of height from the ground and altitude from the sea level mainly in the lower troposphere (4.2.1), effect of the environment on small ion concentrations (4.2.2), other sources for small ions (4.2.3) and temporal variation (4.2.4), as well as observations of the chemical composition of small ions both in the boundary layer and the upper troposphere (4.3).

The measurements presented in this study were conducted all over the world (Table S1, Figs. 2 and 3): in both rural and urban environments in Europe, Asia, America, South-Africa, Australia and Antarctica. Some results from marine environments and high altitudes at mountains are also presented. Table S1 lists references to studies relevant to this review.

\subsection{On the ion production rate via ionisation}

The formation of small ions is limited mainly by the ionisation rate of air molecules. Close to the Earth's surface, the dominant ionisation mechanisms are radon decay and external radiation, which consists of natural and artificial $\gamma$-radiation from the ground and cosmic radiation (Harrison and Aplin, 2001; Szegvary et al., 2007; Hirsikko et al. 2007b, Harrison and Tammet, 2008). The ionisation mechanism and strength are spatially and temporally dependent (e.g. Robertson et al., 2005; Szegvary et al., 2007; Hirsikko et al., 2007b).

Factors affecting radon concentrations include release rates from the surface affected by soil and rock types, radon activity concentration in soil as well as moisture of the soil (e.g. Shashikumar et al., 2008; Szegvary et al., 2009; Mehra et al., 2009; Gupta et al., 2010). The later also affects on terrestrial $\gamma$-radiation, since $\gamma$-photons are absorbed by water (Szegvary et al., 2007). The ionisation rate via radon decay is highly sensitive to the elevation from the ground. In contrast, ionisation due to gamma and cosmic radiation is relatively constant for several tens of meters. Measurements in continental stations show that radon and $\gamma$-radiation are reduced by the snow cover in winter (Hatakka et al., 1998, 2003; Szegvary et al., 2007; Siingh et al., 2007; Hirsikko et al., 2007b).

Galactic cosmic rays (charged particles, i.e. protons) produce ca. 2 ion-pairs $\mathrm{cm}^{-3} \mathrm{~s}^{-1}$ at the ocean surface (Hensen and van der Hage, 1994; Bazilevskaya et al., 2008). Furthermore, galactic cosmic rays are mainly responsible for ion pair production at $3-50 \mathrm{~km}$ altitude, with a maximum rate of $35-$ 50 ion-pairs $\mathrm{cm}^{-3} \mathrm{~s}^{-1}$ at around $15 \mathrm{~km}$ (Rosen et al., 1985; Hoppel and Frick, 1986; Bazilevskaya et al., 2008; Kirkby, 2008). Ion production by galactic cosmic radiation is determined by air density, ionising particle flux and latitude (i.e. the energy of the radiation). The ion pair production is larger in the polar region than at the equator (Hensen and van der Hage, 1994; Bazilevskaya et al., 2008). At high altitudes, solar energetic particles, $\mathrm{X}$-rays and gamma rays have also a contribution to the ion production rates (Bazilevskaya et al., 2008).

The observations of radon activity concentrations, respective ion pair production rates, and total ion production rates calculated according to Eq. (3) reported together with small ion observations are presented in Table S2. For comparison, the average radon activity concentrations reported in literature are typically smaller than $5 \mathrm{~Bq} \mathrm{~m}^{-3}$ (e.g. Hatakka et al., 2003; Ilic et al., 2005; Robertson et al., 2005). Laakso et al. (2004a) compared two methods to evaluate the ion production rates at the SMEAR II station, Finland: (1) direct measurement of radon decay and external radiation, and (2) using the balance equation (Eq. 3) and ion/particle size distribution measurements. The former method led to larger values (Table S2). They argued that it was due to the underestimation of the sink of small ions or the hygroscopic growth factors of the aerosol. In addition, Tammet et al. (2006) showed that the small ions are scavenged by dry deposition onto the forest canopy.

Dhanorkar and Kamra (1994) estimated the maximum small ion concentrations to occure around 04:00 a.m. (local time) in Pune, India, when air mixing is at a minimum 


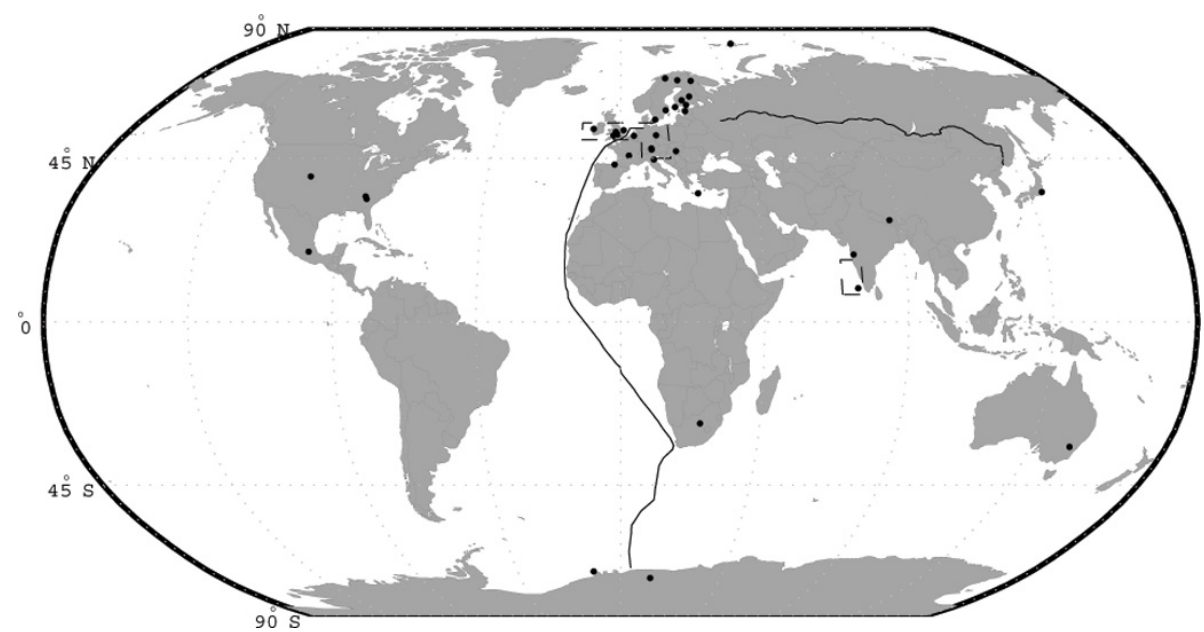

Fig. 2. The map of the world: measurement sites are indicated with black dots, the trip by train through Siberia, Russian, and boat trip from Europe to Antarctica with black curve.

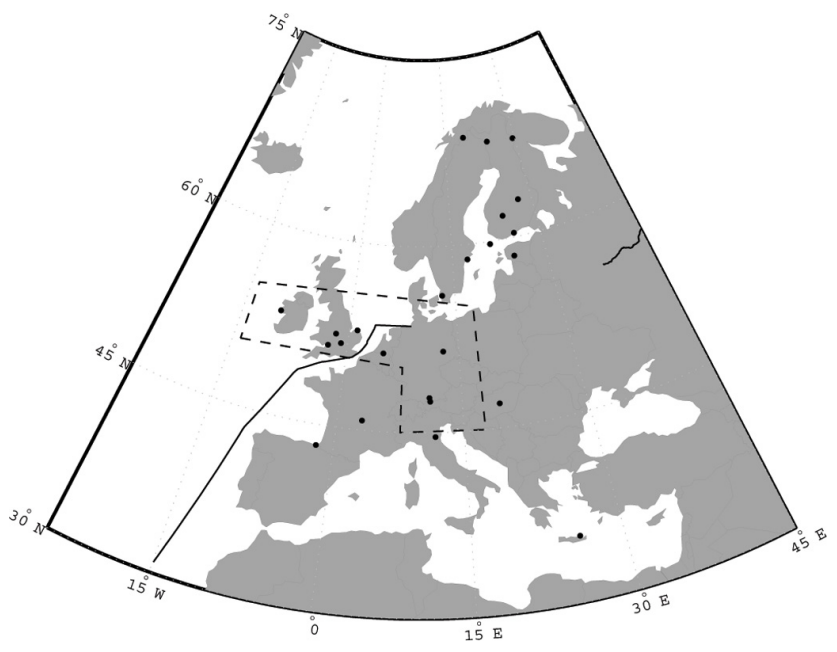

Fig. 3. The map of Europe: measurement sites are indicated with black dots and the aircraft flew inside the area indicated by dashed line. Also the parts of boat and train trips are shown by continuous lines.

and down slope wind blows from the surrounding mountains indicating radon to be mainly responsible for the high values. According to a study by Nagaraja et al. (2003) in Pune, the diurnal variation of directly measured radon concentration and derived ion production rate were in agreement with Dhanorkar and Kamra (1994) results (Table S2). In Tumbarumba, Australia, the ion production rate caused by radon decay was high, with maxima recorded in the early morning (Suni et al., 2008, Table S2). In contrast to radon, the gamma radiation and cosmic radiation do not have a daily cycle.

\subsection{Small ion concentrations}

Table S3 together with Figs. 4-8 summarises observations of small air ions, excluding the results from exhaust and water induced ion experiments in laboratory. Table S3 and Figs. 48 are constructed either based on tables, text or estimations from figures in the references. One must also note that in some studies mobility limit was set so that all small ions were not counted.

Concentrations up to $5000 \mathrm{~cm}^{-3}$ per polarity were observed at some of the sites (Dhanorkar and Kamra, 1993b; Vartiainen et al., 2007). As discussed earlier, such high concentrations require high ionisation rates $(>100$ ion pares $\mathrm{cm}^{-3} \mathrm{~s}^{-1}$ ) and reduced sink due to pre-existing aerosol. Such high concentrations were only observed during short time periods. Thus, the observations are in the limits of the possible ion production rates.

Before the 1950's, there were only a few measurements of air ion mobility distributions in the atmosphere (e.g. Nolan and de Sachy, 1927; Israël and Schulz, 1933; Hogg, 1939; Yunker, 1940; Misaki, 1950; Siksna, 1950). Thus the earliest data shown in Table S3 are from Misaki (1950), and Norinder and Siksna (1950). These are the first measurements made with instruments of adequate sensitivity and accuracy to allow for quantitative comparisons with the modern observations.

\subsubsection{Observations at different heights from the ground and altitudes from the sea level}

Ions of one polarity (usually positive) are drifting in atmospheric electric field downward to the ground and ions of opposite polarity upward. The ground is not emitting the ions and thus only positive ions are present immediately near the surface. Negative ions will appear in some distance from 

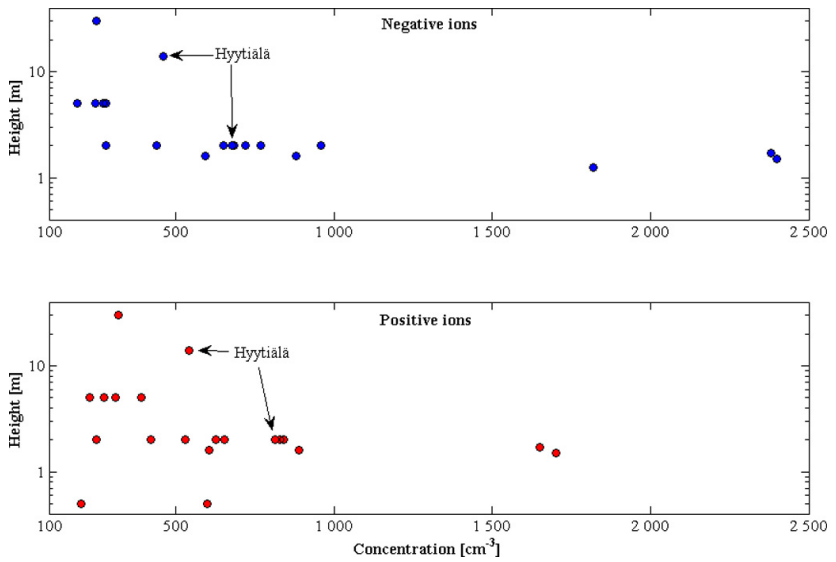

Fig. 4. The mean concentrations as a function of height from the ground. Red colour indicates positive and blue colour negative polarity. Data at $30 \mathrm{~m}$ is from ocean.

the ground due to the ionising radiation. In calm air, which nearly never happens in nature, the height of the layer of prevailing positive ions should be a few meters. Turbulence will mix the air and suppress the effect of electric field, which is called the atmospheric electrode effect.

Typically all the ion measurements have been made at or below the 2-m height (Table S1, Fig. 4), except in Tahkuse, Estonia, where measurements were made at 3 and $5 \mathrm{~m}$ (e.g. Hõrrak et al., 1994). Note that all observations are not included in Fig. 4 due to missing information of measurement height. In Tahkuse the small ion concentrations are one of the smallest observed worldwide. This could be due to the measurement height and thus the reduced effect of radon decay compared to the other sites.

The only study of small ion concentration at two heights ( 2 and $14 \mathrm{~m}$ ) from the ground was carried out in Hyytiälä by Tammet et al. (2006). They found that small ion concentrations were higher at $2 \mathrm{~m}$ than at $14 \mathrm{~m}$ (Table S3, Fig. 4) for two main reasons: (1) the forest canopy is a sink for small ions and (2) the ion production by radon decay is larger closer to the ground.

According to ground based measurements, the median concentration of small ions seemed to decrease with increasing altitude (distance from sea level), whereas the mean concentrations were independent of the altitude (Fig. 5). This is despite the fact that the galactic cosmic radiation produces ca. 2 ion pairs $\mathrm{cm}^{-3} \mathrm{~s}^{-1}$ at sea level, and 5-10 ionpairs $\mathrm{cm}^{-3} \mathrm{~s}^{-1}$ at $5 \mathrm{~km}$ (Bazilevskaya et al., 2008). The contribution of radon may hide the slightly enhancing effect of galactic cosmic radiation on small ion concentration. In addition, the data from Jungfraujoch (at $3500 \mathrm{~m}$ altitude) showed low concentrations of negative small ions compared to positive polarity (Vana et al., 2006b). This was thought to be due to the increased mobility of small ions as the pressure decreases, because the size distributions showed that some of the smallest (especially negative) ions were out of the measurement range. This problem was solved in Airborne NAIS by allowing to changes in flow rate as the ambient pressure varies, and, therefore keeping flow rate to mobility ratio constant (Mirme et al., 2010).

Garmisch-Partenkirchen is the only place where parallel ground-based measurements at two altitudes have been conducted (Reiter, 1985, Table S3). Reiter (1985) reported very low small ion concentrations during fog episodes and periods of high relative humidity in Garmisch-Partenkirchen (1780 $\mathrm{m}$ a.s.l.), when the concentrations of small negative ion decreased nearly to zero, while the small positive ion concentrations remained at a clearly higher level of about $100 \mathrm{~cm}^{-3}$. Reiter (1985) also found that small ion concentrations were the highest during high visibility conditions due to the small scavenging rate of small ions when the air is clean.

The sink effect of clouds is clearly seen at four other sites: (1) Pallas, Finland (Lihavainen et al., 2007), (2) Aboa, Antarctica (Virkkula et al., 2007), (3) Puy de Dôme, France (Venzac et al., 2007), and (4) the High Altitude Research Station at Jungfraujoch, Switzerland (Vana et al., 2006b, Table S3). The observations at the Puy de Dôme mountain (1465 m a.s.l.), which is in the free troposphere, shows that negative ions were more abundant than positive ions during cloudy periods, in contradiction with Reiter (1985). The median concentrations of small negative and positive ions were about $350 \mathrm{~cm}^{-3}$ and $100 \mathrm{~cm}^{-3}$, respectively, during high ambient relative humidity and about $700 \mathrm{~cm}^{-3}$ and $400 \mathrm{~cm}^{-3}$ in clear sky conditions. Venzac et al. (2007) concluded that clouds were the main sink for the small ions. However, in Aboa the negative ions were more efficiently scavenged (Virkkula et al., 2007), in agreement with Reiter (1985). The effect of fog and high moisture, i.e. hygroscopic growth of pre-existing aerosol, was also observed by Hõrrak et al. (2008) at SMEAR II, Finland, where the small ion concentrations reached values less than about $150 \mathrm{~cm}^{-3}$.

Laakso et al. (2007c) measured ion concentration vertical profiles from a hot-air balloon near Hyytiälä, Finland. According to their observations, 1.5-3-nm intermediate ion concentrations were in the range $0-75$ for negative and $0-65$ for positive ions depending on the height from the ground. During their flight over Europe, Kulmala et al. (2010) and Mirme et al. (2010) measured vertical profiles of air ion concentrations. The concentrations of $2.5-3 \mathrm{~nm}$ intermediate ions were highest near the ground, but were nevertheless very low $\left(1-10 \mathrm{~cm}^{-3}\right)$. In addition, concentrations of 0.75 $2 \mathrm{~nm}$ ions were low $\left(100-300 \mathrm{~cm}^{-3}\right)$ but were increasing with increasing altitude up to $4 \mathrm{~km}$. At altitudes higher than $4 \mathrm{~km}$, the results became unreliable due to instrumental issues.

\subsubsection{Observations in different environments}

In different environments, small ion concentrations are affected by the different combinations of production and sink rates. Therefore, in Fig. 6 the mean and median 

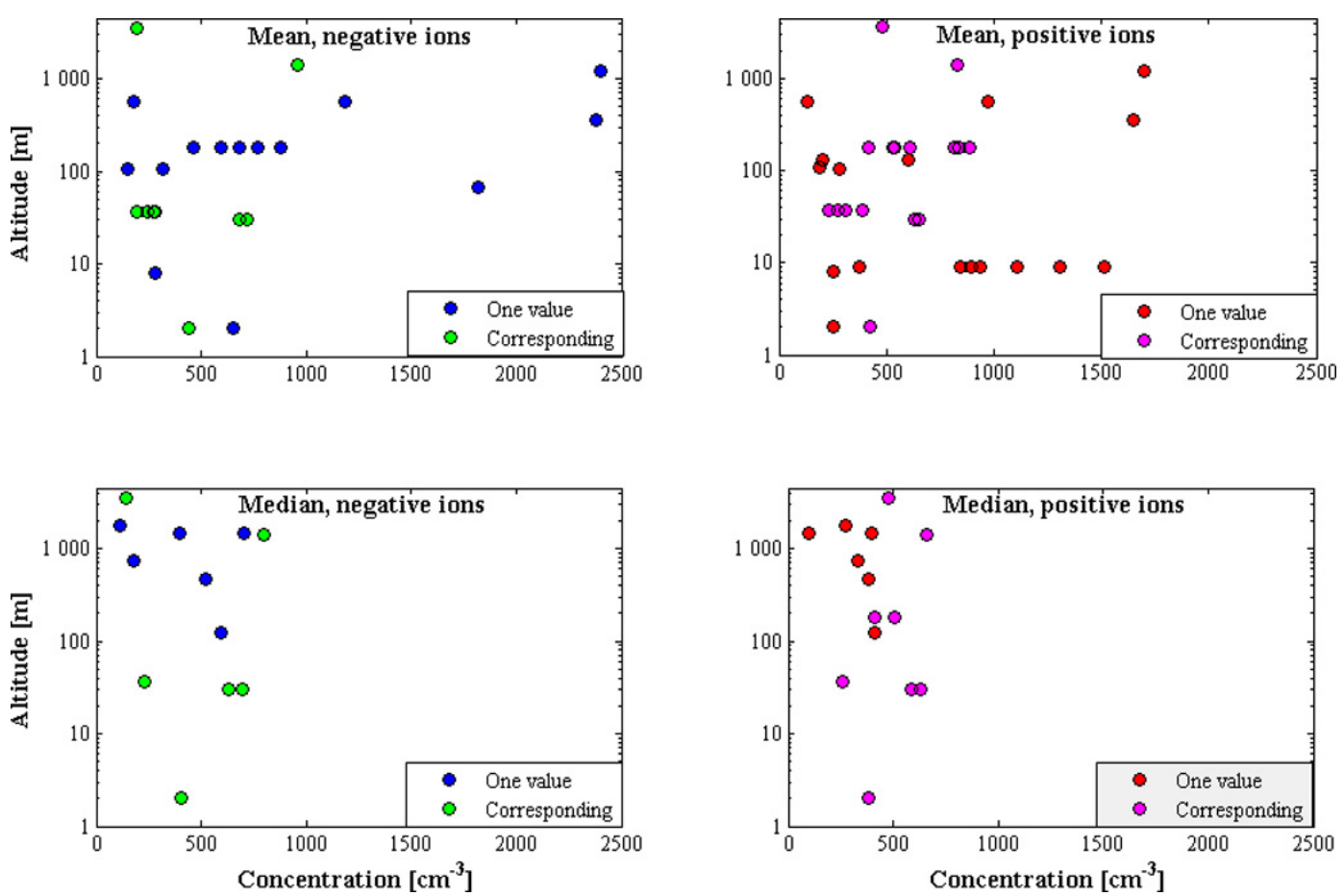

Fig. 5. The mean (top panel) and median (bottom panel) concentrations of positive (right hand side) and negative (left hand side) small ions as a function of altitude from sea level, airborne measurements are not included. The legend "Corresponding" means that both mean and median concentrations were available from specified sites. The legend "One value" means that only mean or median concentration was available. Notice that this division was made separately for both polarities.

concentrations of small ions are presented separately for each measurement site, divided into three types of environments: marine/coastal, urban and rural.

At the shore in San Sebastian, Eichmeier and von Berckheim (1979) measured small ions (mobility $>0.9 \mathrm{~cm}^{2} \mathrm{~V}^{-1} \mathrm{~s}^{-1}$ ) with two ion-counters, one for positive and the other for negative ions. According to their measurements, the average concentrations were 250 and $650 \mathrm{~cm}^{-3}$ for small positive and negative ions, respectively. Observations by Vana et al. (2008) from the coastal site of Mace Head showed that small ion concentrations were smaller when the wind was blowing from the sea than from the land when radon was contributing.

In the beginning of 1960's, Blanchard (1966) measured the space charge with a Faraday cage and the potential gradient by means of a radioactive probe along the shore of Hawaii. $\mathrm{He}$, however, observed a positive space charge and higher values of potential gradient when the air came across the surf zone, while concentrations were close to zero when the wind came over the land. He concluded that the surf is a source of positive charges carried by small water droplets formed via bubble burst at the surface of sea water.

During a cruise from Europe to Antarctica, Vana et al. (2007) observed small ion concentrations to be typically between 100 and $600 \mathrm{~cm}^{-3}$ per polarity. According to observations by Smirnov et al. (1998), three-hour-average concen- trations of small ions from the whole measurement period were $1000-2000 \mathrm{~cm}^{-3}$ per polarity measured with an ion counter UT-840 (from University of Tartu, Estonia) at Zigler Island (Western Arctic, Franz-Joseph Archipelago). Average concentrations $<1000 \mathrm{~cm}^{-3}$ and up to $3000-4000 \mathrm{~cm}^{-3}$ were observed in various wind speeds and directions.

Komppula et al. (2007) compared ion concentrations and their sources and sinks at the marine environment in Utö and two rural continental sites (Hyytiälä, Finland and Tahkuse, Estonia, Table S3). The small ion concentrations were lowest in Utö, where the ion production rate was also the smallest and the sink due to the background aerosol was of the same order as the one measured in Hyytiälä. In Tahkuse, the concentrations were also lower than in Hyytiälä due to a lower ion production rate, since the measurements were done at the 5-m height, and due to a slightly higher aerosol sink. Hirsikko et al. (2005) observed high small ion $(d<1.6 \mathrm{~nm})$ concentrations $\left(200-1500 \mathrm{~cm}^{-3}\right)$ at the rural site of Hyytiälä. The monthly-average concentrations were approximately $600-900 \mathrm{~cm}^{-3}$. Similar concentrations were observed by Dhanorkar and Kamra (1992) at Pune, India (Table S3).

At University of Reading, England, Aplin and Harrison (2000) measured small negative ion concentrations with a Gerdien counter. According to their observations, small ion concentrations were high, on average 1820 and 
$1760 \mathrm{~cm}^{-3}$ for negative ions of mobility larger than 0.77 and $1.08 \mathrm{~cm}^{2} \mathrm{~V}^{-1} \mathrm{~s}^{-1}$, respectively. They obtained similar results from Mace Head. However, using a different instrument (the PIMS) Harrison and Aplin (2007) measured very low small ion concentrations $\left(<200 \mathrm{~cm}^{-3} /\right.$ polarity) at Reading University, England in the summer of 2005.

Wilding and Harrison (2005) used the PIMS at the Norfolk coast. Their results confirm the influence of background aerosol on the mean mobility, concentration and lifetime of small ions, i.e. the larger the background concentration of particles, the smaller the concentration and the lifetime of small ions but the larger the mean mobility. Thus, the small ions attach rapidly onto pre-existing aerosol particles and have therefore little time to grow. The importance of the background aerosol on the small ion concentrations were also confirmed by observations at the polluted urban environment of Athens, Greece (Retalis, 1977; Retalis et al., 2009).

In laboratory, Haverkamp et al. (2004) measured small ion concentrations in the immediate vicinity of a jet aircraft engine exhaust with an ion mobility analyser (IMA). They observed extremely high concentrations of small ions (up to $\left.10^{8} \mathrm{~cm}^{-3}\right)$. Generally, negative ions were smaller than $1500 \mathrm{amu}(1.5 \mathrm{~nm})$ and positive ions smaller than $3000 \mathrm{amu}$ $(1.9 \mathrm{~nm})$. Lähde et al. (2009) were able to measure ion mobility distributions with an AIS in the vicinity of a diesel engine exhaust tailpipe. They observed that without any exhaust after-treatment, the particles had a non-volatile core and the ion size distribution followed the particle size distribution. This implies that the volatile compounds condense on a non-volatile core (of several nanometers) formed in the high temperature and an ionising environment. The results were similar if the exhaust was treated with an oxidation catalyst. However, particles downstream of a diesel particle filter were volatile and neutral, which indicates no contribution of ions to the particle formation process. Jayaratne et al. (2010) observed that car engines operating with unleaded petrol produced an equal amount of positive and negative small ions, and ion concentrations increased with increasing engine speed.

Ling et al. (2010) measured air ions at five different kinds of urban locations in an Australian city: park, woodland, city center, residential area and freeways. The part of their measurements that were affected by power lines, which are known to be a source of unipolar ions, are excluded because they are out of the scope of this review due their quick scavenging rate in the strong electric field, in which they are formed. Furthermore, the concentrations they observed were in agreement with other urban sites (Fig. 6). Vehicles, especially heavy duty trucks, were observed to be sources of ions in both polarities, while the woodlands were thought to be the sources of volatile organics and biogenic precursors for nucleation. There was a difference in concentrations between the polarities in the park and the city centre.

On the sea South West of India, Gopalakrishnan et al. (2005) measured charged particle size distributions, and found that both small (up to $2500 \mathrm{~cm}^{-3}$ ) and intermediate ion concentrations increased when sampling from ship exhausts (Table S3). However, according to Tiitta et al. (2007) small ion concentrations decreased, although measuring in immediate vicinity of the road, when the wind was from the nearby road in Kuopio, Finland. The observations by Tiitta et al. (2007) are contrary to the observations reported by Ling et al. (2010) and Jayaratne et al. (2010). However, the small ion concentrations have been observed to decrease to the background level in some tens of meters depending on the wind speed, the aerosol particle concentration and the dilution ( $\mathrm{Ja}-$ yaratne et al., 2010).

Hirsikko et al. (2007c) measured air ion size distributions both indoors and outdoors in urban Helsinki. At a car parking area $100 \mathrm{~m}$ away from a major road, the outdoor small ion concentrations (medians 590 and 630 for positive and negative polarity, respectively, Table S3) and sinks were somewhat higher than at the rural Hyytiälä site. The small ion concentrations were dependent on wind direction and the sink due to pre-existing particles, whereas intermediate and large ion concentrations were affected by traffic density of the nearby road and wind direction. The diurnal cycle of indoor small ion concentrations (medians 966 and 1065 for positive and negative polarity, respectively, Table S3) was affected by ventilation, being the highest during night with very little or no ventilation (Hirsikko et al., 2007c). Therefore, they expected that the source rate of small ions by radon activity (ca. 12 ion-pairs $\mathrm{cm}^{-3} \mathrm{~s}^{-1}$ ) was elevated indoors. Earlier measurements over short period made by Fews et al. (2005) showed similar small ion concentrations for indoor air.

Comparatively high small ion concentrations were observed in Abisko, Sweden, where mean concentrations for positive and negative ions were 1650 and $2380 \mathrm{~cm}^{-3}$, respectively (Svennigsson et al., 2008), as well as in Tumbarumba, Australia, where mean concentrations for positive and negative ions were 1700 and $2400 \mathrm{~cm}^{-3}$, respectively (Suni et al., 2008). Abisko is surrounded by and next to mountains, and thus the atmospheric conditions are different as compared with more flat and open areas. The observed high concentrations in Tumbarumba were thought to be due to enhanced radon efflux compared to many other sites, while the aerosol sink was quite low compared to other rural sites like Hyytiälä (Suni et al., 2008). Vartiainen et al. (2007) also observed high concentrations during a train trip through Russia.

\subsubsection{Other sources for small ions}

After the accident in the nuclear power plant at Chernobyl on 26 April 1986, Hõrrak et al. (1994) observed that the concentrations of positive and negative small ions began to increase rapidly from the background $\left(300 \mathrm{~cm}^{-3}\right)$ and reached a maximum $\left(800 \mathrm{~cm}^{-3}\right)$ on 1 May 1986 , slowly decaying afterwards to reach a concentration of $400 \mathrm{~cm}^{-3}$ a month later. The observations from Uppsala, Sweden (Israelsson and Knudsen, 1986), and Athens, Greece (Retalis and Pitta, 

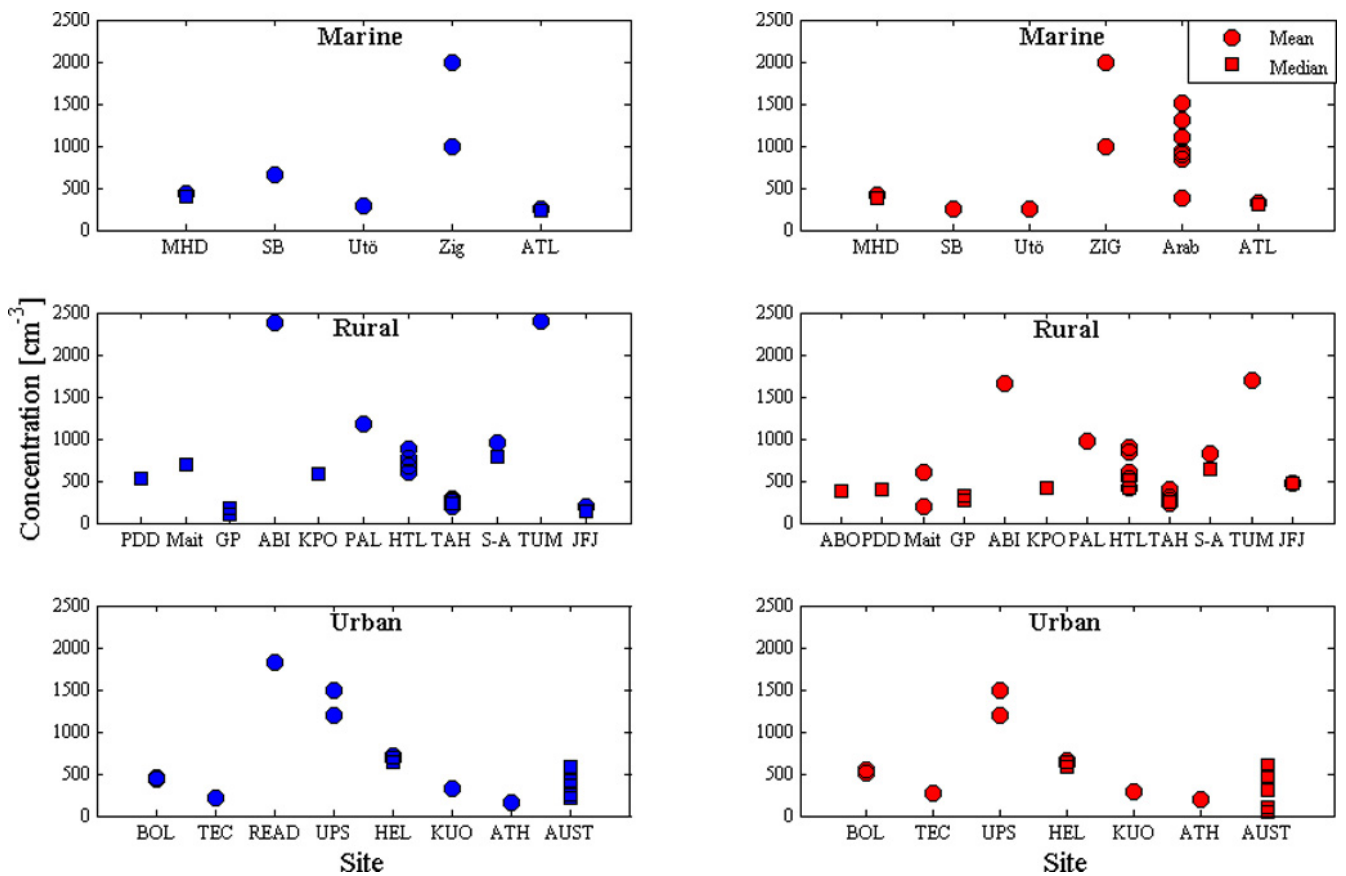

Fig. 6. The mean and median concentrations of small ions as a function of site in marine (top panel), rural (middle panel) and urban (bottom panel) environments based on measurements on the ground. Red markers are for positive and blue markers for negative ions. $\mathrm{MHD}=$ Mace Head, $\mathrm{SB}=\mathrm{San} \mathrm{Se}=$ Puy de Dôme, Mait = Maitri, GP=Garmisch-Partenkirchen, $\mathrm{ABI}=\mathrm{Abisko}, \mathrm{KPO}=\mathrm{K}-\mathrm{Puzsta}$, $\mathrm{PAL}=$ Pallas, $\mathrm{HTL}=$ Hyytiälä, $\mathrm{TAH}=$ Tahkuse, $\mathrm{S}-\mathrm{A}=$ South-Africa, $\mathrm{TUM}=$ Tumbarumba, $\mathrm{ABO}=\mathrm{Aboa}, \mathrm{JFJ}=\mathrm{Jungfraujoch}, \mathrm{BOL}=\mathrm{Boulder}$, TEC $=$ Tecamac, Read. $=$ Reading University, Ups $=$ Upsala, HEL $=$ Helsinki, KUO $=$ Kuopio, ATH $=$ Athens and AUST $=$ Australia $($ Ling et al., 2010).

1989), support the observations from Tahkuse. Thus, a couple of days after the accident, air conductivity, which is directly proportional to small ion concentration, increased by an order of magnitude in both Sweden and Greece due to the increased radioactive radiation. According to Retalis and Pitta (1989), the concentration of positive small ions increased from the normal level of $200 \mathrm{~cm}^{-3}$ up to $700 \mathrm{~cm}^{-3}$.

Waterfalls (Laakso et al., 2007b) and rainfall (Norinder and Siksna, 1950; Hõrrak et al., 2006, Hirsikko et al., 2007a; Vana et al, 2008) produce high concentration of ions, especially negatively-charged ions smaller than $10 \mathrm{~nm}$. The rainfall phenomenon is more frequent with negative intermediate ions, which concentrations typically increase immediately after the beginning of the rainfall. Positive intermediate ions are observed after the rain has continued for a longer period (Hirsikko et al., 2007a; Junninen et al., 2008). The phenomenon of rainfall induced ions is known as the Lenard effect and Tammet et al. (2009) studied the phenomenon via so called balloelectric ions (i.e. the generation of charge by splashing water), with mobilities of $0.1-0.42 \mathrm{~cm}^{2} \mathrm{~V}^{-1} \mathrm{~s}^{-1}$. The main outcome of their laboratory study was that these balloelectric ions are singly charged water nanoparticles. Although they could generate the phenomenon in the laboratory, the exact mechanism of the formation of balloelectric ions remains unknown.
Virkkula et al. (2007) found that concentrations of small and intermediate ions increased with high wind speeds (up to $40 \mathrm{~m} \mathrm{~s}^{-1}$ ) and when snow was drifting or falling in Antarctica. A similar increase in ion concentrations during high winds was also observed by Vana et al. (2006b) at the High Altitude Research Station at Jungfraujoch in Switzerland. Virkkula et al. (2007) and Vana et al. (2006b) argued that the additional ions were formed by friction when snow and ice crystals are transported at high speeds by the wind. However, at wind speeds below $10 \mathrm{~m} \mathrm{~s}^{-1}$ opposite observations have been made (e.g. Siingh et al.; 2007; Kamra et al., 2009).

\subsubsection{On the temporal variation of small ion concentrations}

Many studies have reported enhanced concentrations of small ions during early morning hours due to the accumulation of radon (e.g. Dhanorkar and Kamra, 1994). Norinder and Siksna (1950) observed the highest small ion concentrations (ca. $3000 \mathrm{~cm}^{-3}$ ) in early morning hours (ca. 04:00 a.m. local time) in Sweden, while the average was $1200-1500 \mathrm{~cm}^{-3}$. Dhanorkar and Kamra (1993a) observed that the concentrations of ions in every mobility/size interval were highest early in the morning in Pune, India. Similar results were obtained in their other study at the same site (Dhanorkar and Kamra, 1993b). In Tokyo, Misaki (1961b) 
observed high small ion concentrations early in the morning just before sunrise. Based on three days of data, small ion concentrations were $100-600 \mathrm{~cm}^{-3}$ both in the rural Karuizawa and the urban Tokyo sites (Table S3).

Junninen et al. (2008) reported increases in both concentration and mean size of small ions observed in a boreal forest environment in Hyytiälä during night-time. These increases were most frequent on nights following a new particle formation event day, suggesting a possible contribution from the same vapours in both day and night-time growth. Furthermore, Siingh et al. (2005) observed higher night-time than day time concentrations in fair weather conditions during their cruise on the Arabian Sea.

Retalis et al. (2009) observed with their ion counters (by Laboratory in Physics in Aarau, Switzerland) very low small ion concentrations in Athens, Greece. Concentrations typically reached a maximum early in the morning, indicating the enhanced contribution of radon decay. Concentrations reached a minimum in the daytime due to the increased sink onto the background aerosol. Later, the background aerosol was diluted and the small ion concentrations increased again. Furthermore, the mean annual concentrations of negative and positive ion concentrations decreased from 170 and $210 \mathrm{~cm}^{-3}$, respectively, to 130 and $170 \mathrm{~cm}^{-3}$, respectively in 17 years.

At Himalaya, Nepal (5079 $\mathrm{m}$ a.s.l. in free the troposphere) concentrations of up to $3000 \mathrm{~cm}^{-3}$ were observed (Venzac et al., 2008). The small ion concentrations increased before a new particle formation event and decreased after the event was over. Moreover, clearly lower $\left(<500 \mathrm{~cm}^{-3}\right)$ concentrations were observed between the events. More typically, the opposite has been observed, i.e. decrease in small ion concentrations during particle formation (e.g. Hõrrak et al., 2000, 2003; Nieminen et al., 2009; Gagné et al., 2010). The explanation for this kind of adverse temporal variation can be similar as observed by Vana et al. (2006b).Thus, the mobility of small ions increases as the ambient pressure decreases, and more ions were out of the measurement range during non-event periods than during particle formation events, when the small ions have grown in size.

During the monsoon period, small ion concentrations above the Arabian Sea decreased by almost an order of magnitude compared to those in the pre monsoon period, whereas the concentration of large ions increased (Pawar et al., 2005; Siingh et al., 2005, Table S3). This was thought to be due to high wind speeds accompanied by the bubbling of the white caps. Furthermore, the small ion concentrations first increased and then began to decrease when the distance from the coast increased prior to the monsoon period (Siingh et al., 2005). Radon transported from the coastal sand was thought to be responsible for the pre monsoon observations. Such a clear trend was missing during the monsoon. Siingh et al. (2005) showed that the small ion concentrations increased, while intermediate ion concentrations decreased, during drizzle-type rain. In contrast to other observations
(Norinder and Siksna, 1950; Hõrrak et al., 2006; Hirsikko et al., 2007a; Vana et al, 2008), the concentrations of ions in all size classes decreased during heavy rain.

\subsection{Observations on the chemical composition of air ions}

The composition of air ions reacts to changes in the trace atmospheric gases rapidly, with negative charges acquired by the compounds that have the lowest proton affinities, and positive charges acquired by the compounds having the highest proton affinities. Arnold et al. (1978) measured the composition of positive ions smaller than $330 \mathrm{amu}$ with the balloon-borne mass spectrometers at 33-37 km above SouthWest France. According to their results, two families of ion species exist in the stratosphere, called proton hydrates and non-proton hydrates (with fractions of $0.43 / 0.57$ ), although both families contain protons $(\mathrm{H})$. Typical proton hydrates were $\mathrm{H}^{+}\left(\mathrm{H}_{2} \mathrm{O}\right)_{3}, \mathrm{H}^{+}\left(\mathrm{H}_{2} \mathrm{O}\right)_{4}, \mathrm{H}^{+}\left(\mathrm{H}_{2} \mathrm{O}\right)_{5}$, and non-proton hydrates were $\mathrm{H}^{+} \mathrm{x}\left(\mathrm{H}_{2} \mathrm{O}\right)_{2}, \mathrm{H}^{+} \mathrm{x}\left(\mathrm{H}_{2} \mathrm{O}\right)_{3}, \mathrm{H}^{+} \mathrm{x}\left(\mathrm{H}_{2} \mathrm{O}\right)_{4}$. Based on their results, Arnold et al. (1978) proposed acetonitrile as possible candidate for compound marked with $\mathrm{x}$.

Ferguson (1978) disagreed with Arnold et al. (1978) about the existence of acetonitrile in the stratosphere. According to Ferguson (1978), the observed non-proton hydrates (Arnold et al., 1978) would rather be sodium hydroxide cluster ions $\left(\mathrm{NaOH}_{2}+\left(\mathrm{H}_{2} \mathrm{O}\right)_{w}(\mathrm{NaOH})_{m}\right.$, where $m=0 \ldots 4$ and $w=0 \ldots 2$ ). Regarding negative ions, Arnold (2008) found that negative ions in the stratosphere were more likely to contain sulphuric and nitric acids $\left(\mathrm{NO}_{3}^{-}\left(\mathrm{HNO}_{3}\right)_{n}\left(\mathrm{H}_{2} \mathrm{O}\right)_{w}\right.$ and $\left.\mathrm{HSO}_{4}^{-}\left(\mathrm{H}_{2} \mathrm{SO}_{4}\right)_{a}\left(\mathrm{H}_{2} \mathrm{O}\right)_{w}\right)$.

Eichkorn et al. (2002) measured the composition of large positive ions, i.e. smaller than $2500 \mathrm{amu}$ or ca. $1.7 \mathrm{~nm}$ in diameter, with an aircraft-based large ion mass spectrometer (LIOMAS) at 9-10 km over Europe. They found three types of positive ions in the upper troposphere: $(1) \mathrm{H}^{+} \mathrm{B}_{b}\left(\mathrm{H}_{2} \mathrm{O}\right)_{w}$, where $\mathrm{B}$ is most likely acetone $\left(\left(\mathrm{CH}_{3}\right)_{2} \mathrm{CO}\right)$ and $\mathrm{b} \leq 2$, (2) $\mathrm{H}^{+} \mathrm{B}_{b}\left(\mathrm{H}_{2} \mathrm{SO}_{4}\right)_{a}\left(\mathrm{H}_{2} \mathrm{O}\right)_{w}$, and (3) $\mathrm{H}^{+} \mathrm{B}_{b}\left(\mathrm{H}_{2} \mathrm{O}\right)_{w}$-ions attached to $\left(\mathrm{H}_{2} \mathrm{SO}_{4}\right)_{x}\left(\mathrm{H}_{2} \mathrm{O}\right)_{y}$ neutral clusters. Eichkorn et al. (2002) proposed that $\left(\mathrm{H}_{2} \mathrm{SO}_{4}\right)_{\mathrm{x}}\left(\mathrm{H}_{2} \mathrm{O}\right)_{\mathrm{y}}$ clusters were formed by an ion-induced process.

Eisele et al. (1989a) measured the gas phase ion composition by mass spectrometry at the Forestry Commission site close to Dawsonville, Georgia, USA. They found that the four most abundant species of negative atmospheric ions were $\mathrm{NO}_{3}^{-}(m / z=62), \mathrm{NO}_{3}^{-} \cdot \mathrm{HNO}_{3}(\mathrm{~m} / z=125)$, $\mathrm{C}_{3} \mathrm{H}_{3} \mathrm{O}_{4}^{-} \cdot \mathrm{HNO}_{3}(\mathrm{~m} / \mathrm{z}=166)$ and $\mathrm{HSO}_{4}^{-} \cdot \mathrm{H}_{2} \mathrm{SO}_{4}(\mathrm{~m} / \mathrm{z}=195)$. In addition, $\mathrm{HSO}_{4}^{-} \cdot\left(\mathrm{H}_{2} \mathrm{SO}_{4}\right)_{2} \quad(\mathrm{~m} / z$ 293) clusters, $\mathrm{C}_{3} \mathrm{H}_{3} \mathrm{O}_{4}^{-} \quad(m / z=103), \mathrm{NO}_{3} \mathrm{SO}_{3}^{-}(\mathrm{m} / \mathrm{z} \quad 142)$ and $\mathrm{NO}_{3} \mathrm{SO}_{4}^{-}$ $(m / z=158)$ were also observed (Eisele et al., 2006). The most abundant identified positive ion species were $m / z=60$, 70 and 130, identified as trimethylamine, isoxazole and isoquinoline, respectively (Eisele, 1989b).

In the urban Helsinki environment at SMEAR III, using a Atmospheric Pressure Interface Time-of-Flight Mass 
Spectrometer (APi-TOF), Junninen et al. (2010) observed the negative ion daytime spectrum to be dominated by inorganic acids (nitric, sulphuric and iodic acids). Two main ion groups (alkyl amines and alkyl pyridines) for positive ions were observed. Ehn et al. (2010) measured the ion chemical composition with the APi-TOF in Hyytiälä. During daytime particle formation, the negative ion spectrum was dominated by sulphuric acid and di-, tri- and tetramer sulphuric acid clusters. They also observed sulphuric acid tetramer-ammonia ions. The night-time negative ion spectrum was thought to contain highly-oxygenated organic acids, possibly from the oxidation of monoterpenes. Through ion measurements, Ehn et al. (2010) were the first to observe gas phase organosulphates. Although the positive ion spectrum was spread out over a large amount of peaks, Ehn et al. (2010) could determine that the spectra consisted of species like alkyl pyridines, quinolines, alkyl amines, pyrroles and pyrrolines during both day and night.

\section{Ions and atmospheric new particle formation}

Atmospheric new-particle formation by nucleation may take place thermodynamically, kinetically or by the activation of pre-existing nanometer-size clusters. Nucleation is driven by sulphuric acid and possibly other low-volatile vapours (e.g. organics) (e.g. Clarke et al., 1999; Sihto et al., 2006; Kulmala et al., 2006; Riipinen et al., 2007, 2009; Kuang et al., 2008; Sipilä et al., 2010), in addition, it may be assisted by ammonia and other bases (e.g. Weber et al., 1996, 1997, 1998, 1999; Eisele and McMurry, 1997; Kerminen et al., 2010) as well as by ions (e.g. Froyd and Lovejoy, 2003a, b; Lovejoy et al., 2004; Nadykto and Yu, 2004; Enghoff et al., 2008; Yu, 2010).

Ion-induced nucleation usually means nucleation in the presence of electric charges, while ion-mediated particle formation also takes into account the ion-ion recombination in the small ion size range. As concluded by Laakso et al. (2002), Curtius et al. (2006) and Yu (2010), ion-mediated particle formation mechanisms are expected to be important in locations with low temperature and pre-existing aerosol surface area, together with high relative humidity, ion and sulphuric acid concentrations. These kinds of conditions are typically encountered in the middle and upper troposphere, and even in the lower troposphere (including the boundary layer) as well as in the lower stratosphere (Arnold, 1982; Lee et al., 2003; Kanawade and Tripathi, 2006; Manninen et al., 2010; Yu, 2010). Higher up in the stratosphere, there is insufficient super saturation of any vapour for the classical ion-induced particle formation mechanism to produce growing condensation nuclei (Arnold, 1980), so most condensation nuclei are thought to originate from the troposphere or may be of meteoritic origin from extraterrestrial regions (Cadle and Kiang, 1977).
This section discusses ions in association with atmospheric new particle formation events. After considering what kind of general information ion measurements can provide on atmospheric nucleation events (Sect. 5.1), we will briefly review the observed formation rates of 2-nm ions and neutral particles, as well as observed particle growth rates based on ion measurement (Sect. 5.2). The role of ions in the actual nucleation process will be discussed in Sect. 5.3.

\subsection{Monitoring the aerosol particle formation events by ion measurements}

The lessons that can be learned about the first steps of particle formation based on size distribution data for larger particles $(\sim 10 \mathrm{~nm}$, for example) are limited because the particles have typically been growing already for several hours before they were detected. Because data of ion mobility distributions provide information on the processes at the sizes as they occur, they provide valuable insights into mechanisms of particle formation and growth. For example, Venzac et al. (2008) were able to confirm that new particle formation took place in situ at the Himalayas (at $5079 \mathrm{~m}$ a.s.1.). Similar observations were made at other free troposphere sites, such as at Puy de Dôme in France (1465 m a.s.l., Venzac et al. 2007), as well as through the whole boundary layer (Laakso et al., 2007c). Furthermore, differences in the concentrations of positive and negative ions during nucleation bursts can provide clues about the roles of ions in particle formation as well as chemistry related to particle formation.

Hirsikko et al. (2007a) modified the method used typically for DMPS data (Dal Maso et al., 2005) to classify charged particle formation events. Further refinements to the classification scheme by Hirsikko et al. (2007a) have also been published for specified sites (e.g. Virkkula et al., 2007; Vana et al., 2008; Suni et al., 2008; Yli-Juuti et al., 2009; Manninen et al., 2009a). These schemes involve classifying the particle formation events into groups according to: (1) the strength of the particle formation event, (2) the extent to which particles grow (i.e. does growth stop at $3-10 \mathrm{~nm}$ or do the new intermediate ions grow within the nucleation mode), and (3) whether or not a gap is observed in the size distribution between small ions and intermediate ions. Moreover, other types of days can be classifdied as: (4) non-event days, and (5) rain-induced intermediate ions. This method was used to study new particle formation events based on DMPS and BSMA measurements in the boreal pine forest in Finland. Hirsikko et al. (2007a) found that the ion spectrometer could detect particle formation events that were suppressed, due to low concentrations of condensing vapours or high sink by pre-existing aerosol particles, before the DMPS (detection limit $>3 \mathrm{~nm}$ ) detected any particles.

Junninen et al. (2008) continued the work of Hirsikko et al. (2007a) by studying particle formation events taking place during the night-time, i.e. nocturnal events. Nocturnal events were typically suppressed at the lower limit of the DMPS 
size range (around 2-5 nm) due to the lower concentration of condensing vapours and the coagulation loss of slowly growing ions. Junninen et al. (2008) observed that the nocturnal events occurred more frequently for negative ions in winter, indicating that negative ions require less condensing vapours than positive ones, or that negative ions have greater affinity for the condensing vapours. These conclusions are in agreement with laboratory observations by Winkler et al. (2008). In other times of the year, such a clear difference was not observed. Furthermore, Junninen et al. (2008) found that on 90 days when particle formation occurred, it was also observed in the following night, while after about 28 non-event days only one particle formation event took place in the night. The nocturnal particle formation events were independent of ambient weather conditions and air mass origin but dependent on small ion and sulphuric acid concentrations. Junninen et al. (2008) concluded that particle formation mechanisms or vapours participating in particle formation and growth are different on day- and night-time. Lehtipalo et al. (2011) showed that the night-time events in Hyytiälä are seen equally frequently for neutral particles, and that the night-time concentrations of sub- $3 \mathrm{~nm}$ particles and ions have a clear connection to oxidised organic molecules.

At the Stordalen mire in Abisko, particle formation could take place several times during a day, and night-time events were also observed (Svenningsson et al., 2008). Photochemical reactions or boundary layer reactions were assumed not to be the main driving factors of these nocturnal events (Svenningsson et al., 2008). In Tumbarumba, Southern Australia, nocturnal new particle formation was observed on $32 \%$ of the analysed nights and the phenomenon was estimated to be an important particle source (Suni et al, 2008; Lee et al., 2008). One must note that new particles were typically able to grow during the nocturnal events both in Sweden and Australia, unlike at the SMEAR II station in Finland. According to Lee et al. (2008), nocturnal particle formation takes place throughout the tropospheric column. Suni et al. (2009) continued their earlier work and observed the inflow of clean and dry air from polar ocean together with terpene emissions from vegetation to contribute the most on new particle formation events. These results are in accordance with earlier observations for day-time events in the boreal forest (Sogacheva et al., 2005).

During the EUCAARI campaign the special focus was on observations of particle formation events and the role ions in the formation process (Sects. 5.2.2 and 5.3). The measurements were carried out with various instruments (AIS, NAIS, BSMA, Ion-DMPS) able to detect sub-3 $\mathrm{nm}$ particles at the 12 European sites (Manninen et al., 2010; Kerminen et al., 2010). The frequency of particle formation event days ranged from $20 \%$ to $60 \%$ of the days in Pallas and Melpitz, respectively (Manninen et al., 2010). The highest particle formation frequencies were observed in rural central European sites and in coastal Mace Head (Table S3).
Laakso et al. (2008) presented one of the first results of ion and particle size distribution measurements in Africa at a rural background site in the Savannah. They observed particle formation on over $90 \%$ of the days. Vakkari et al. (2010) continued this analysis for longer period and ended up with a bit smaller percentage (83\%) of particle formation events. Also at Aboa, Antarctica, particle formation has been observed (Virkkula et al., 2007; Asmi et al., 2010). Vana et al. (2007) observed only one particle formation event during their cruise from Europe to Antarctica when the ship was in a pack-ice region.

New particle formation was also observed indoors in laboratory air in Helsinki (Hirsikko et al., 2007c). Based on their ion size distribution and total particle concentration data, Hirsikko et al. (2007c) concluded that indoor new particle formation was only slightly dependent on outdoor air, i.e. there were enough condensing vapours available indoors in this special case. Also, measurements of air ions in urban environments like in a park in Australia (Ling et al., 2010) and in Helsinki, Finland (Hirsikko et al., 2007c) showed that new particle formation took place locally.

\subsection{Aerosol formation and growth rates}

\subsubsection{The estimation of formation and growth rates}

The total (neutral + charged) formation rates of 2-nm particles can be calculated as (Kulmala et al., 2007)

$$
\begin{aligned}
J_{2}[\text { tot }]= & \frac{d N_{2-3}[\text { tot }]}{d t} \\
& +\operatorname{Coag} S_{2} \cdot N_{2-3}[\text { tot }]+\frac{f}{1 \mathrm{nn}} \mathrm{GR}_{3} \cdot N_{2-3}[\mathrm{tot}],
\end{aligned}
$$

and the simplified balance Eq. (4) for ions can be improved to be able to calculate the formation rates of 2-nm ions (Kulmala et al., 2007)

$$
\begin{aligned}
J_{2}^{ \pm}[\text {ion }]= & \frac{d N_{2-3}^{ \pm}[\text {ion }]}{d t}+\operatorname{Coag} S_{2} \cdot N_{2-3}^{ \pm}[\text {ion }] \\
& +\frac{f}{1 \mathrm{~nm}} \mathrm{GR}_{3} N_{2-3}^{ \pm}[\text {ion }]+\alpha N_{2-3}^{ \pm}[\text {ion }] N_{<3}^{ \pm}[\text {ion }] \\
& -\beta \cdot N_{2-3} N_{<2}^{ \pm}[\text {ion }] .
\end{aligned}
$$

Thus, the formation rates of new 2-nm particles/ions are equal to sum of the time changes in the number concentration of $2-3 \mathrm{~nm}$ particles/ions (the first terms on right hand side), the coagulation loss of $2-3 \mathrm{~nm}$ particles/ions with the pre-existing aerosol (the second terms), the growth of 2-3 nm particles/ions into larger sizes with growth rate (GR) and activation fraction to growth $f$ (the third terms). In addition, ions are lost via ion-ion recombination (the fourth term on the right) and formed via ion-neutral attachment (the fifth term). Typically, the coefficients $\alpha$ and $\beta$ are $1.6 \times 10^{-6} \mathrm{~cm}^{3} \mathrm{~s}^{-1}$ 
and $0.01 \times 10^{-6} \mathrm{~cm}^{3} \mathrm{~s}^{-1}$, respectively (Israel, 1970; Hoppel, 1985; Hoppel and Frick, 1986). Equations (10) and (11) describe the formation rates of total and charged 2-nm particles, as derived from measured quantities, but do not contain information on how ions and neutral particles/clusters smaller than $2 \mathrm{~nm}$ in diameter interact with each other below $2 \mathrm{~nm}$.

There are several ways to estimate ion/particle growth rates (GR[ion] and GR[tot]) based on ion mobility/particle size distribution data. Lehtinen and Kulmala (2003), Kulmala et al. (2004b) and Hirsikko et al. (2005) described a method to also obtain the GR[ion] of the smallest ions. The method, which is commonly used by the group at the University of Helsinki for both ion and particle size distribution data, is based on determining the maximum concentration of each selected size bin as a function of time by fitting a Gaussian curve. From these time-diameter pairs, the growth rate can be calculated for any size range.

The main problem is to estimate the growth of the smallest particles correctly. Indeed, the coagulation of small particles with pre-existing aerosol particles may cause the apparent (i.e. calculated) GRs to exceed the true GRs (Hirsikko et al., 2005; Stolzenburg et al., 2005). In addition, Hirsikko et al. (2005) noted that self-coagulation is also excluded from the analysis, which causes some error in the results if concentrations are high (Stolzenburg et al., 2005; Anttila et al., 2010). Ions have similar enhancing effects on the calculated GR[tot]. When introducing this method to obtain the GR, Lehtinen and Kulmala (2003) pointed out that the growth seems to be linear, which means that a constant amount of vapour contributes to the growth process. Kulmala et al. (2004b) noted that this method leads to an uncertainty factor of two.

The other method to obtain GR[ion] or GR[tot], used by University of Helsinki researchers, is to fit log-normal modes into the size distribution data (see Hussein et al., 2005; Dal Maso et al., 2005). Again, the growth rate is obtained as a slope of the line fitted to the diameter vs. time data. This method assumes that the air mass is homogeneous and that all the particles are formed at the same time. Svenningsson et al. (2008) used this method with their ion data measured with the AIS in Abisko, Sweden.

Iida et al. (2008) introduced a new method using air ion data to determine the GR of particles that involved comparing size-dependent charged fractions with their stationary state values. They assumed that the particle charge is determined by competing rates of particle growth, coagulation, and charging by small ions. If particles grew very slowly, they would acquire the stationary state distribution, and no additional information about growth rates could be determined from the charged fractions. Useful information, however, can be obtained if particles grow fast enough, and thus their original (under or over) charging state was visible (Kerminen et al., 2007). In Mexico City, where neutral processes appear to dominate nucleation, charged fractions for sub $10 \mathrm{~nm}$ particles were below stationary state values, but approached stationary state as the particles grew (Iida et al., 2008). Because they only measured the charged fractions for particles larger than about $3.7 \mathrm{~nm}$, they were only able to obtain information on growth rates for particles above that threshold. However, this approach could also be used for smaller particles if charged fraction data were available. An advantage of this approach is that the GR can be determined from a single measurement of size-dependent charged fractions.

\subsubsection{Observations}

The observed total formation rate $\left(J_{2}[\right.$ tot $\left.]\right)$ of neutral and charged 2-nn particles has been observed to vary in the range of $0.001-60 \mathrm{~cm}^{-3} \mathrm{~s}^{-1}$ depending on the particle formation event (Table S3). However, the formation rate of 2-nm ions ( $J_{2}$ [ion]) has been found to exceed $1 \mathrm{~cm}^{-3} \mathrm{~s}^{-1}$ only at the South-African Savannah (Table S3 and Fig. 7). Note that the small $J_{2}$ [ion] (order of $10^{-6} \mathrm{~cm}^{-3} \mathrm{~s}^{-1}$ ) values from Hyytiälä, Finland, presented by Laakso et al. (2007c) are out of the range in Fig. 7. According to Kulmala et al. (2010), Manninen et al. (2010) and Gagné et al. (2010), the contribution of ions increases as a function of decreasing formation rate of the whole 2-nm population.

The growth rates of sub- $3 \mathrm{~nm}$ ions were somewhat different at various sites (Table S3 and Fig. 8). Particle growth rates seem to be size dependent, i.e. small particles tend to grow slower than large particles in Hyytiälä (Dal Maso et al., 2005; Hirsikko et al., 2005). Similar results were obtained at K-Puszta (Yli-Juuti et al., 2009) and during the EUCAARI measurement period at 12 European sites (Manninen et al., 2010). Different factors could contribute to this size dependence. Particles grow with time, so this apparent dependence on size could be due to changes in the chemical processes that occur during the day. It is also possible that the growth rates vary with size at a given time due to the effect of size on vapour uptake. An understanding of particle growth kinetics will require an understanding of the relationships between the gas phase compounds that contribute to the growth and the size-dependent rate at which they accumulate in particles. This demands for advances in the measurements of both the particle composition and the gas phase aerosol precursors.

Vakkari et al. (2010) studied new particle formation events measured with an AIS in the South-African Savannah. They observed a different kind of size dependence in the particle growth. Generally, 3-7 nm ions grew faster than 7-20 nm ions, while the growth of the smallest ions was the slowest as in other sites. This kind of size dependence of growth can be due to the time dependence of condensing vapours. In winter, the growth of 1.5-3 nm ions can be the faster than the growth of larger particles, as reported by Hirsikko et al. (2005), Suni et al. (2008) and Manninen et al. (2010). This could be due to the enhancing effects due to ions in particle formation (Yu and Turco, 2000; Kulmala et al., 2004b), when air temperature and sometimes the particle sink are lower, thereby 

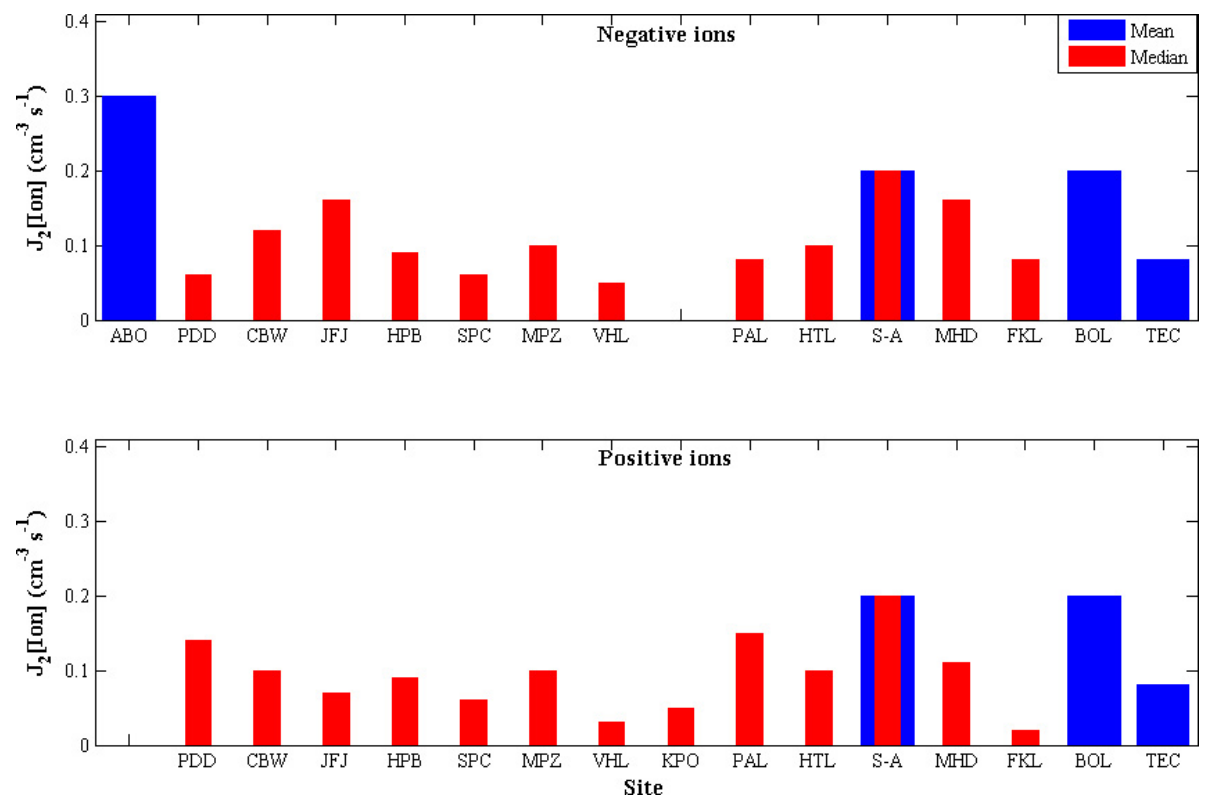

Fig. 7. The mean (blue bar) and median (red bar) $J_{2}$ [ion] as a function of site in rural, marine and urban environments for negative ions (top panel) as well as for positive ions (bottom panel). $\mathrm{ABO}=\mathrm{Aboa}, \mathrm{PDD}=\mathrm{Puy}$ de Dôme, $\mathrm{CBW}=\mathrm{Cabauw}, \mathrm{JFJ}=\mathrm{Jungfraujoch}$, $\mathrm{HPB}=$ Hohenpeissenberg, SPC $=$ San Pietro Capofiume, MPZ = Melpitz, VHL = Vavihill, PAL = Pallas, HTL = Hyytiälä, S-A = South-Africa, $\mathrm{MHD}=$ Mace Head, FKL $=$ Finokalia, $\mathrm{BOL}=$ Boulder, $\mathrm{TEC}=$ Tecamac .

favouring ion-mediated processes (Curtius et al., 2006; Yu 2010). However, the growth rates of sub-3 $\mathrm{nm}$ ions are almost constant throughout the year, while the growth of larger particles is reduced in winter and enhanced in summer (Hirsikko et al., 2005; Vakkari et al., 2010).

Hirsikko et al. (2007c) estimated similar growth rates for sub-3 $\mathrm{nm}$ ions in the outdoor and indoor air of urban Helsinki as in the rural Hyytiälä air (Hirsikko et al., 2005). However, somewhat higher growth rates were observed in Helsinki, which were thought to be due to low condensation sinks, high concentrations of condensing vapours and the important role of ions.

Furthermore, according to Table S3, the GRs[ion] of few nanometer ions were similar at every site, except in Stordalen mire, Sweden, where Svenningsson et al. (2008) observed one of the quickest growth rates of 1-10-nm ions during their measurements: up to $40 \mathrm{~nm} \mathrm{~h}^{-1}$. Furthermore, the high GR coexisted with the high condensation sink values, which was unexpected and indicates very high source rates of condensable vapours.

Sulphuric acid together with some other low volatile vapours (e.g. ammonia, amines, organics) are believed to be involved in the particle formation process and in particle growth as fast growth rates as observed (e.g. Weber et al., 1996, 1997, 1998, 1999; Hirsikko et al., 2005, Yli-Juuti et al., 2009; Dal Maso et al., 2005, 2009; Paasonen et al., 2009, 2010; Ristovsky et al., 2010). Arnold (2008) concluded that in the upper troposphere organics are irrelevant, while sulphuric acid may contribute due to the long life-time of $\mathrm{SO}_{2}$.
Kuang et al. (2010) showed that in locations throughout the troposphere, sulphuric acid accounted for between $1 \%$ and $100 \%$ of the growth of freshly nucleated particles, with average values in the 5-10\% range. According to the air mass and sulphuric acid proxy studies in South Africa, Vakkari et al. (2010) concluded that sulphuric acid contributes 20$30 \%$ on the growth of the smallest ions and $10-20 \%$ to the growth of larger than $3 \mathrm{~nm}$ ions and particles. Smith and coworkers developed the thermal desorption chemical ionisation mass spectrometer (TDCIMS) to measure the composition of freshly nucleated particles as small as $8 \mathrm{~nm}$ (Voisin et al., 2003; Smith et al. 2005, 2008, 2010). They found that organic salts, formed by the reactions of amines with organic acids, account for $20 \%-50 \%$ of the growth, and the contributions from other organic compounds were also important.

Gagné et al. (2010) studied particle formation with an IonDMPS in Hyytiälä, Finland. They observed the GRs[ion] were independent of the contribution of ions in particle formation, whereas GR[tot] and the sulphuric acid saturation ratio seemed to be higher on days when ions were less important in particle formation.

\subsection{The role of ions in atmospheric nucleation}

The recent measurements with various ion spectrometers and Ion-DMPS have brought plenty of new insight into the role of ions in the nucleation process. Firstly, from NAIS measurements one may calculate the maximum contribution of ion-mediated nucleation to the overall nucleation rate using 

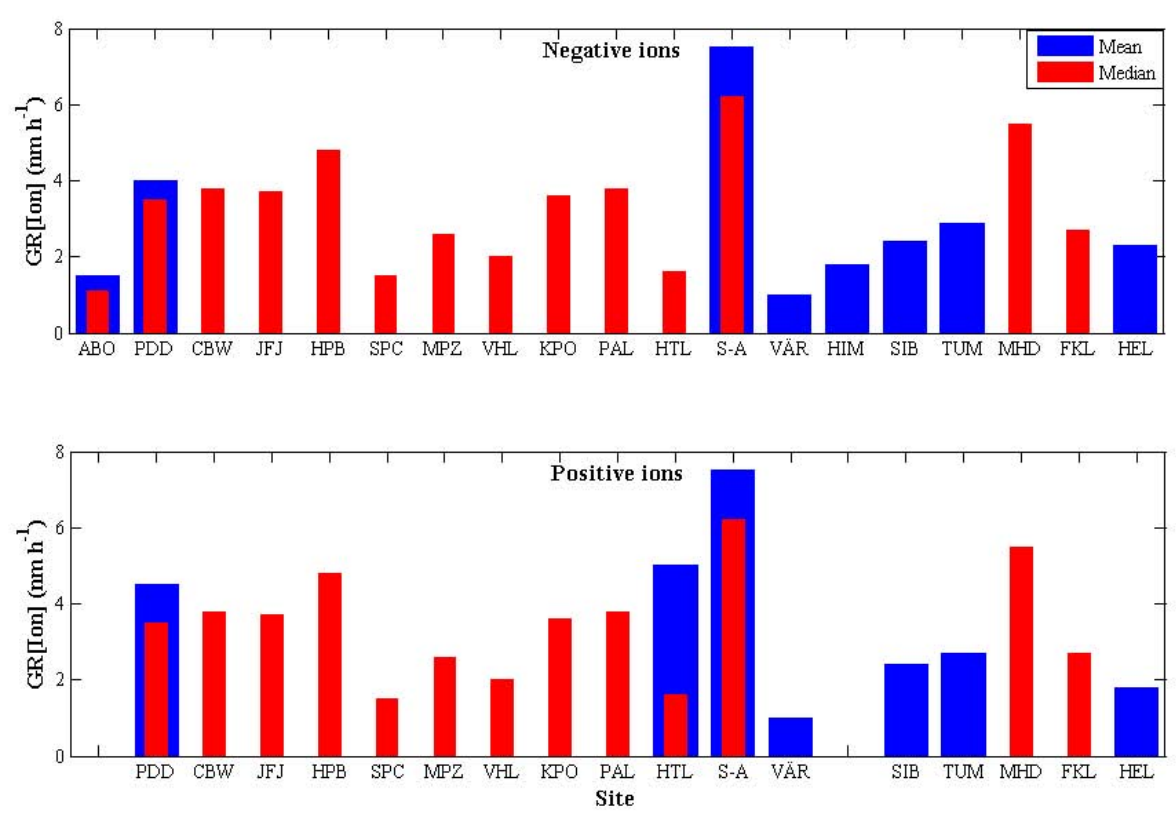

Fig. 8. The mean (blue bar) and median (red bar) GR[ion] as a function of site in rural, marine and urban environments for negative ions (top panel) as well as for positive ions (bottom panel). ABO = Aboa, PDD = Puy de Dôme, $\mathrm{CBW}=$ Cabauw, JFJ $=$ Jungfraujoch, HPB = Hohenpeissenberg, $\mathrm{SPC}=$ San Pietro Capofiume, $\mathrm{MPZ}=\mathrm{Melpitz}, \mathrm{VHL}=\mathrm{Vavihill}, \mathrm{PAL}=\mathrm{Pallas}$, $\mathrm{HTL}=$ Hyytiälä, TAH = Tahkuse, S-A = South-Africa, VÄR = Värriö, HIM = Himalaya, SIB = Siberia, TUM=Tumbarumba, MHD = Mace Head, FKL $=$ Finokalia, $\mathrm{HEL}=$ Helsinki.

the following equation:

maximum ion - mediated fraction $=\frac{J_{2}^{+}[\text {ion }]+J_{2}^{-}[\text {ion }]+J_{2}[\text { rec }]}{J_{2}[\text { tot }]}$

Here $J_{2}$ [tot] and $J_{2}^{ \pm}$[ion] are given by Eqs. (10) and (11) presented in Sect. 5.2.1, and $J_{\text {rec }}$ is the recombination rate of sub-2 $\mathrm{nm}$ ions. The corresponding minimum contribution of ion-mediated nucleation, called the "ion-induced fraction" by Manninen et al. (2010) and "ion-induced contribution" by Gagné et al. (2008), is obtained by setting $J_{\text {rec }}$ equal to zero in Eq. (12). Secondly, the Ion-DMPS measures directly the charging state of particles larger than $3 \mathrm{~nm}$ in mobility diameter (see Sect. 3.2), from which the contribution of ionmediated nucleation can be estimated using the theoretical framework by Kerminen et al. (2007). Thirdly, the temporal evolution of concentrations of different-size ions during the nucleation events provides complementary, yet indirect, information on the role of ions in atmospheric nucleation.

By using the Ion-DMPS and AIS/NAIS at the SMEAR II station, Manninen et al. (2009a) studied the charging state and ratio of concentrations of total population and ions $\left(\mathrm{Conc}_{\mathrm{tot}} / \mathrm{Conc}_{\text {ion }}\right)$ in the $1.8-3 \mathrm{~nm}$ size range. They showed that the negative and positive ion overcharging was accompanied with a decrease in the ratio of concentrations on $51 \%$ and $34 \%$ of particle formation days, respectively. This is indicative of the importance of ions in particle formation on such days. Also Gagné et al. (2010) used the Ion-DMPS to investigate the charging state of newly formed aerosol particles. They found that overcharged particle formation events are frequent throughout the year, while undercharged events are being observed more frequently from November to January. They concluded that the overcharged days are observed typically on dryer and warmer days, with higher solar radiation than the undercharged days, and that the overcharged days are more frequent for the negative polarity than for the positive one. Additionally, the nucleation mode particle (3-25 nm) concentrations seem to be higher during undercharged days, which is in accordance with Vana et al. (2006). Gagné et al. (2010) and Nieminen et al. (2009) reported a decrease in the small ion concentrations during particle formation events. Such a decrease can be due to ion-induced nucleation or increased sink after new particle formation.

According to the observations by Hirsikko et al. (2007a) at the SMEAR II station, negative ions were sometimes favoured over the positive ones, since more particle formation events were observed in the negative polarity than in the positive one. Based on the measurements from April 2003 to March 2006, during 19 and 6 particle formation events observed for only positive and negative ions, respectively, there was a gap in the size distribution between the small and intermediate ions. This indicates the dominance of neutral mechanisms over ion-induced pathways during particle formation (see Leppä et al., 2009). 
In some cases, ion-mediated processes have been observed to be important at the beginning of the events and the one ion polarity to be favoured over the otherone (Laakso et al., 2007a, c; Manninen et al., 2010). During particle formation event taking place at the SMEAR II station, small ions seem to activate earlier than neutral 2-nm particles (Laakso et al., 2007c; Manninen et al., 2009b; 2010). This is in accordance with the laboratory observations that small ions activate at lower super saturation than neutral ones (Winkler et al., 2008).

In spite of the frequent involvement of ions in the nucleation process (Manninen et al., 2009a), the ion-induced fraction has been observed to be on average $10 \%$ of the total 2$\mathrm{nm}$ particle formation at the SMEAR II station in Hyytiälä (Manninen et al., 2009b). Kulmala et al. (2010) reported that ion-induced fraction was about $10 \%$ of the 2-nm particle formation in Hyytiälä, Hohenpeissenberg and Melpitz rural continental sites, which is consistent with other studies (e.g. Kulmala et al., 2007; Manninen et al., 2010). Gagné et al. (2008) obtained similar contributions of ions in particle formation in Hyytiälä based on their charging state measurements: median value of $6.4 \%$ with range $1.7-16.5 \%$. Similarly, nocturnal particle formation seems to be driven by neutral mechanism in Hyytiälä, Finland (Lehtipalo et al., 2011). Iida et al. (2006) estimated that the contribution of positive ion-induced particle formation was $0-3.8 \%$ and negative ion formation was 0-2.6\% during their measurements in Boulder, Colorado, USA.

Higher ion-induced fractions have been observed in some environments, such as in the high-altitude site Jungfraujoch and Pallas where the average ion-induced fraction was ca. $30 \%$ and $20 \%$, respectively (Manninen et al., 2010). Asmi et al. (2010) observed a new particle formation event in Antrarctica using both AIS and DMPS, and during that event the ion-induced fraction was about $30 \%$ of the total particle formation rate.

Based on aircraft measurements, Kulmala et al. (2010) and Mirme et al. (2010) concluded that the contribution of ions to 2-nm particle formation is minor for the whole tropospheric column. Contrary to this, Arnold (2008) estimated that ion-induced nucleation could be the dominant process at altitudes of ca. $8 \mathrm{~km}$ over Central Europe with a maximum particle formation rates of $25 \mathrm{~cm}^{-3} \mathrm{~s}^{-1}$, which is the same as the maximum ion production rate via ionisation at $8 \mathrm{~km}$ (Bazilevskaya et al., 2008). Arnold (2008) concluded that neutral and ion-induced nucleation is frequent phenomena in the upper troposphere, but further growth is limited.

The ion-ion recombination taking place below $2 \mathrm{~nm}$ limits our ability to estimate the contribution of ion-mediated nucleation to the total nucleation rate. Lehtipalo et al. (2009) studied small neutral particles by subtracting small ion concentrations from the total small particle concentrations measured with a Pulse Height Condensation Particle Counter (Saros et al., 1996) operated at a high saturation ratio to allow the activation of sub-2 nm particles (e.g. Sipilä et al., 2008,
2009). Lehtipalo et al. (2009, 2010) showed that ion-ion recombination can explain only a minor fraction of the high concentrations of small neutral particles that were detected in Hyytiälä, Finland, which is supported by the results of Manninen et al. (2009a). In Mace Head when the air masses came from the ocean, a significant fraction, and at night-time even all of the particles in the size range $1.3-3 \mathrm{~nm}$ could be ions and their recombination products (Lehtipalo et al., 2010).

Based on above, the measurements conducted in continental boundary layers are indicative of frequent, yet moderate, ion-mediated nucleation outweighed usually by much stronger neutral nucleation events. Model studies tend to predict a large contribution of ion-mediated (or charged) nucleation to the total nucleation rate in the global troposphere (e.g. Kazil et al., 2010; Yu et al., 2010), and in some cases model simulations seem to be in conflict with deductions made from field measurements (Yu and Turco, 2008). The main reason for these apparent discrepancies is that the interactions between sub- 2 to $3 \mathrm{~nm}$ ions and neutral particles are complicated and not yet well characterized. This results in substantial uncertainties in modeling the ion-mediated nucleation process, as well as in deriving ion-mediated nucleation rates from atmospheric observations. Furthermore, there are still considerable uncertainties in measuring the formation and growth rates of charged and neutral $2 \mathrm{~nm}$ particles. Resolving these uncertainties and discrepancies requires both theoretical and experimental approaches to tackle the dynamics of sub 3-nm population of ions and neutral particles.

\section{Concluding remarks}

This review is based on ca. 260 publications, from which 93 articles presented observations on small air ions and size distribution measurements, chemical composition as well as formation and growth rates of sub- $3 \mathrm{~nm}$ ions. Our main focus was on the spatial and temporal variation of small ion concentrations, and the secondary focus was in the observations of the role of ions on nucleation and growth.

The main natural sources of small ions are air molecule ionisation by radon decay, gamma and cosmic radiation, all of them exhibiting strong spatial and temporal variations. This variability of ion source rates is evident from the comparison of results from different sites. In marine environments, the only important source of small ions is cosmic radiation and the low source rates lead to lower concentrations of small ions than are found in terrestrial environments.

Most of the concentration measurements have been made in the boundary layer, excluding the high altitude sites like Puy de Dôme, France, and Pyramid in Himalaya, Nepal, which are affected by free troposphere conditions. The ground based median concentrations of small ions seem to decrease with increasing altitude, even though the mean concentrations did not depend on altitude. The enhanced radon 
activity concentration was observed to be behind the temporal increase in small ion concentrations observed at certain sites (e.g. Hõrrak et al., 2003; Dhanorkar et al., 1994; Suni et al., 2008). However, the potential enhancing effect of cosmic radiation induced ion production (Chalmers, 1967) and decreasing back-ground aerosol concentration resulting in the increased concentration of small ions as a function of altitude in the lower atmosphere remained without confirmation. The airborne measured small ion concentration profiles, however, showed increasing trend as a function of altitude (Mirme et al., 2010).

The enhancing effect of car exhaust on small ion concentrations has been confirmed in the laboratory (Haverkamp et al., 2004; Lähde et al., 2009). Some studies revealed increased small ion concentrations due to traffic (Ling et al., 2010), while some others observed even a decrease in concentration due to traffic (Tiitta et al., 2007). Due to enhanced recombination and coagulation with aerosol particle emitted from cars, Hirsikko et al. (2007c) observed a decrease in small ion concentrations if the wind had passed through a major road, $100 \mathrm{~m}$ away. These conclusions were supported by observations by Jayaratne et al. (2010). Additionally, falling water droplets and sea sprey bursts have been observed to increase ion concentrations (e.g. Blanchard, 1966; Hirsikko et al., 2007a; Laakso et al., 2007b; Tammet et al., 2009).

Sinks of small ions include recombination, loss by growth to larger sizes and coagulation with the pre-existing aerosol particles. The growth and coagulation processes vary significantly with time. Small ion measurements inside the forest confirm an additional sink due to ion deposition in the forest canopy (Tammet et al., 2006). High aerosol concentrations, such as those found in polluted urban environments, act as increased sinks for small ions (e.g. Retalis et al., 2009; Ling et al., 2010). However, the aerosol sink in some of the urban environments was not substantially increased (e.g. Hirsikko et al., 2007c). Clouds were observed to be effective sinks for small ions (Reiter et al., 1985; Lihavainen et al., 2007; Venzac et al., 2007; Virkkula et al., 2007). Each observation site had different combinations of sink and production terms for small ions.

The effect of electric charge can lead to enhanced growth rates of the smallest particles (e.g. Yu and Turco, 2000; Kulmala et al., 2004b). Enhanced growth of sub-3 nm ions has been observed at least at the coastal site Mace Head, Ireland (Manninen et al., 2010), as well as in winter at SMEAR II, Finland (Hirsikko et al., 2005) and in Tumbarumba, Australia (Suni et al., 2008). However, usually the growth of sub-3 $\mathrm{nm}$ ions is the slowest (Kulmala et al., 2004b; Hirsikko et al., 2005: Virkkula et al., 2007: Suni et al., 2008: YliJuuti et al., 2009; Manninen et al., 2010), indicating that ionmediated mechanisms would be less important compared to neutral processes in particle growth (Kulmala et al., 2004b). The growth rate results are often presented as median or average values over a month, and the information about each individual event is lost. Furthermore, it has been observed that on days when ion-mediated processes are almost nonexistent, 3-7 nm particles grow faster than on days with some contribution of ions, while the growth rates of ions were independent of the role of ions in the particle formation (Gagné et al., 2010). The enhanced growth of 3-7 nm particles on days when formation rates were high and ions had unsubstantial contribution, may be explained by enhanced saturation ratios of condensing vapours. Thus, changes in condensable vapour compositions and concentrations as a function of time of the day and season may explain the observed size dependence of the growth rates.

Ion-mediated nucleation has been observed in chamber experiments (e.g. Froyd and Lovejoy, 2003a,b; Enghoff et al., 2008; Duplissy et al., 2010). Atmospheric observations suggest, however, that the ion-mediated fraction of 2-nm particle formation is usually small compared to neutral pathways, approximately $10 \%$ or even less of the total at various European rural, urban and coastal sites (e.g. Gagné et al., 2008; Kulmala et al., 2010, Manninen et al., 2009b, 2010) and less than 5\% during summertime events in Boulder (Iida et al., 2006).

The observations from Antarctica (Asmi et al., 2010) support the theory of an enhancing effect of low temperature and aerosol surface area to ion-mediated particle formation processes (Curtius et al., 2006; Yu 2010). The observations by Gagné et al. (2010), however, show that overcharged events took place during warmer days in Hyytiälä, Finland, while undercharged days occurred on colder days.

At low total formation rates of 2-nm particles, the ionmediated mechanism could explain the observed nucleation rates and the observations that ion concentrations (charged fraction) decrease with increasing total particle formation rates (Vana et al., 2006; Nieminen et al., 2009; Kulmala et al., 2010; Gagné et al., 2010, Manninen et al., 2010). The largest variation was found in the $J_{2}$ [tot], whereas $J_{2}$ [ions] was typically below $1 \mathrm{~cm}^{-3} \mathrm{~s}^{-1}$ in the boundary layer (e.g. Manninen et al., 2010). On the other hand, ions may contribute only for a short time at the beginning of the particle formation event and become less important as time progresses and neutral mechanisms take over (Laakso et al., 2007a). Ion-mediated particle formation pathway is limited by the ion production rate, being, however an important 2-nm particle formation mechanism under certain conditions, as discussed in this review.

At high altitudes, the ion pair production rate by galactic cosmic radiation shows an 11-year cycle opposite to the solar cycle (Bazilevskaya et al., 2008). The overview by Harrison and Carslaw (2003) discuss the effect of ions on cloud formation and processes therein. References cited in that overview show that the albedo of the planet varies in phase with the solar cycle. There have also been studies about the possible connection between the galactic cosmic ray intensity reaching the Earth's atmosphere and the global cloud cover (e.g. Kirkby, 2008). Galactic cosmic rays ionise air 
molecules, and thus could potentially affect the production of cloud condensation nuclei in the atmosphere. The changes in the activity of our Sun modulate the amount of galactic cosmic rays coming to Earth, and this could serve as a mechanism for altering the global cloud cover and, consequently, climate. This connection is currently, however, unclear and under active research (Kirkby, 2008; Duplissy et al., 2010). In contrast, the solar cycle seems to have no influence on secondary particle formation or ion production rates close to the Earth's surface, as observed in the boreal forest (Kulmala et al., 2010).

This review concentrated on observations in the lower troposphere due to very limited number of observations in the upper troposphere. In future, we need to further improve our understanding of the evolution of small ions in the atmosphere to be able to evaluate the role of ions in particle formation. Therefore, developments are needed in the theoretical understanding of small ion balance in the atmosphere, as well as in the instrumentation used for detecting the size and mass spectra of neutral, especially, nanometer-sized particles and clusters (e.g. Iida et al., 2009; Lehtipalo et al., 2010). The improvement of theoretical approaches requires comprehensive information on small ions in different environments, including their: (1) chemical composition (e.g. Eisele 1989a, b; Junninen et al., 2010; Ehn et al., 2010, 2011), (2) vertical concentration profiles (e.g. Mirme et al., 2010; Laakso et al., 2007c), and (3) source and sink rates. This kind of information can be obtained, for example, via: (1) parallel measurements of the ion size distribution, radon activity concentration and gamma radiation, (2) measurements in vicinity of local sources, e.g. corona dischargers and roads (e.g. Eisele, 1989a,b; Jayaratne et al., 2010), (3) parallel measurements of ions and neutral nano-particles, (4) laboratory studies (e.g. CLOUD experiment in CERN, Duplissy et al., 2010), and (5) airborne measurements from a balloon or aeroplane.

\section{Supplementary material related to this article is available online at: http://www.atmos-chem-phys.net/11/767/2011/ acp-11-767-2011-supplement.pdf.}

Acknowledgements. Anne Hirsikko acknowledges Maj and Tor Nessling foundation for their grant (No. 2007116). The funding from the Academy of Finland Center of Excellence program (Project number 1118615), the European Commission 6-th Framework project EUCAARI (European Integrated project on Aerosol Cloud Climate and Air Quality Interactions, No 036833-2), and the European Research Council (Project number 227463-ATMNUCLE) are kindly acknowledged. Dr. Kenijiro Iida analysed his data from Boulder, Colorado and Tecamac, Mexico to obtain the results presented in this review. McMurry acknowledges support from the U.S. National Science Foundation (Grant No. ATM-0506674), and the U.S. Department of Energy (Grant No. DE-FG-02-05ER63997). The co-authors from the University of
Tartu would like to thank the support of the Estonian Science Foundation under grant No. 8342 and the Estonian Research Council Project SF0180043s08.

Edited by: A. Wiedensohler

\section{References}

Anttila, T., Kerminen, V.-M., and Lehtinen, K. E. J.: Parameterizing the formation rate of new particles: The effect of nuclei selfcoagulation, J. Aerosol Sci., 41, 621-636, 2010.

Aplin, K. L. and Harrison, R. G.: A computer-controlled Gerdien atmospheric ion counter, Rev. Sci. Instrum., 71, 3037-3041, 2000.

Arnold, F.: Multi-ion complexes in the stratosphere-implications for trace gases and aerosol, Nature, 284, 610-611, 1980.

Arnold, F.: Ion nucleation-a potential source for stratospheric aerosols, Nature, 299, 134-135, 1982.

Arnold, F.: Atmospheric Ions and Aerosol Formation, Space Sci. Rev., 137, 225-239, 2008.

Arnold, F., Böhringer, H., and Henschen, G.: Composition measurements of stratospheric positive ions, Geophys. Res. Lett., 5, 653-656, 1978.

Asmi, E., Sipilä, M., Manninen, H.E., Vanhanen, J., Lehtipalo, K., Gagné, S., Neitola, K., Mirme, A., Mirme, S., Tamm, E., Uin, J., Komsaare, K., Attoui, M., and Kulmala, M.: Results on the first air ion spectrometer calibration and intercomparison workshop, Atmos. Chem. Phys., 9, 141-154, doi:10.5194/acp-9-141-2009, 2009.

Asmi, E., Frey, A., Virkkula, A., Ehn, M., Manninen, H. E., Timonen, H., Tolonen-Kivimäki, O., Aurela, M., Hillamo, R., and Kulmala, M.: Hygroscopicity and chemical composition of Antarctic sub-micrometre aerosol particles and observations of new particle formation, Atmos. Chem. Phys., 10, 4253-4271, doi:10.5194/acp-10-4253-2010, 2010.

Bazilevskaya, G. A., Usoskin, I. G., Flückiger, E. O., Harrison, R. G., Desorgher, L., Bütikofer, R., Krainev, M. B., Makhmutov, V. S., Stozhkov, Y. I., Svirzhevskaya, A. K., Svirzhevsky, N. S., and Kovaltsov, G. A.: Cosmic Ray Induced Ion Production in the Atmosphere, Space Sci. Rev., 137, 149-173, 2008.

Blanchard, D. C.: Positive Space Charge from the Sea, J. Aerosol Sci., 23, 507-515, 1966.

Cadle, R. D. and Kiang, C. S.: Stratospheric Aitken particles, Rev. Geophys., 15(2), 195-202, 1977.

Chalmers, J. A.: Negative electric fields in mist and fog, J. Atmos. Terr. Phys., 2, 155-159, 1952.

Chalmers, J. A.: Atmospheric Electricity, Pergamon Press, Oxford, London, 515 pp., 1967.

Chapman, S. and Cowling, T.G.: The mathematical theory of nonuniform gases, Cambridge University Press, Cambridge, 1970.

Clarke, A. D., Kapustin, V. N., Eisele, F. L., Weber, R. J., and McMurry, P. H.: Particle Production near Marine Clouds: Sulfuric Acid and Predictions from Classical Binary Nucleation, Geophys. Res. Lett., 26(16), 2425-2428, 1999.

Coulomb, C. A.: Troisième Mémoire sur l'Electricité et le Magnétisme, Histoire de l'Académie Royale des Sciences, l'Acad'emie Royale des Sciences Paris, 612-638, 1785. 
Curtius, J., Lovejoy, E. R., and Froyd, K. D.: Atmospheric ioninduced aerosol nucleation, Space Sci. Rev., 125, 159-167, 2006.

Dal Maso, M., Kulmala, M., Riipinen, I., Wagner, R., Hussein, T., Aalto, P. P., and Lehtinen, K. E. J.: Formation and growth of fresh atmospheric aerosols: eight years of aerosol size distribution data from SMEAR II, Hyytiälä, Finland, Boreal Environ. Res., 10, 323-336, 2005.

Dal Maso, M., Hari, P., and Kulmala, M.: Spring recovery of photosynthesis and atmospheric particle formation, Boreal Environ. Res., 14, 711-721, 2009.

Dhanorkar, S. and Kamra A. K.: Relation between electrical conductivity and small ions in the presence of intermediate and large ions in the lower atmosphere, J. Geophys. Res., 97, 2034520360, 1992.

Dhanorkar, S. and Kamra, A. K.: Diurnal variations of the mobility spectrum of ions and size distribution of fine aerosols in the atmosphere, J. Geophys. Res., 98, 2639-2650, 1993a.

Dhanorkar, S. and Kamra, A. K.: Diurnal and seasonal variations of the small-, intermediate-, and large-ion concentrations and their contributions to polar conductivity, J. Geophys. Res., 98, 1489514908, 1993b.

Dhanorkar, S. and Kamra, A. K.: Diurnal variation of ionization rate close to ground, J. Geophys. Res., 99, 18523-18526, 1994.

Duplissy, J., Enghoff, M. B., Aplin, K. L., Arnold, F., Aufmhoff, H., Avngaard, M., Baltensperger, U., Bondo, T., Bingham, R., Carslaw, K., Curtius, J., David, A., Fastrup, B., Gagné, S., Hahn, F., Harrison, R. G., Kellet, B., Kirkby, J., Kulmala, M., Laakso, L., Laaksonen, A., Lillestol, E., Lockwood, M., Mäkelä, J., Makhmutov, V., Marsh, N. D., Nieminen, T., Onnela, A., Pedersen, E., Pedersen, J. O. P., Polny, J., Reichl, U., Seinfeld, J. H., Sipilä, M., Stozhkov, Y., Stratmann, F., Svensmark, H., Svensmark, J., Veenhof, R., Verheggen, B., Viisanen, Y., Wagner, P. E., Wehrle, G., Weingartner, E., Wex, H., Wilhelmsson, M., and Winkler, P. M.: Results from the CERN pilot CLOUD experiment, Atmos. Chem. Phys., 10, 1635-1647, doi:10.5194/acp-101635-2010, 2010.

Ebert, H.: Aspirationsapparat zur Bestimmung des Ionengehalts der Atmosphäre, Phys. Z., 2, 662-664, 1901

Ehn, M., Junninen, H., Petäjä, T., Kurtén, T., Kerminen, V.-M., Schobesberger, S., Manninen, H. E., Ortega, I. K., Vehkamäki, H., Kulmala, M., and Worsnop, D. R.: Composition and temporal behavior of ambient ions in the boreal forest, Atmos. Chem. Phys., 10, 8513-8530, doi:10.5194/acp-10-8513-2010, 2010.

Ehn, M., Junninen, H., Schobesberger, S., Manninen, H. E., Franchin, A., Sipilä, M., Petäjä, T., Kerminen, V.-M., Tammet, H., Mirme, A., Mirme, S., Hõrrak, U., Kulmala, M., and Worsnop, D. R.: An Instrumental Comparison of Mobility and Mass Measurements of Atmospheric Small Ions, Aerosol Sci. Technol., 45, 4, 522-532, 2011.

Eiceman, G. A. and Karpas, Z.: Ion Mobility Spectrometry, CRC Press, Boca Raton, FL, 2005.

Eichkorn, S., Wilhelm, S., Aufmhoff, H., Wohlfrom, K. H., and Arnold, F.: Cosmic ray-induced aerosol-formation: First observational evidence from aircraft-based ion mass spectrometer measurements in the upper troposphere, Geophys. Res. Lett., 29(14), 1698, doi:10.1029/2002GL015044, 2002.

Eichmeier, J. und Braun, W.: Beweglichkeitsspektrometrie atmosphärischer Ionen, Meteorol. Rundsch., 25, 14-19, 1972.

Eichmeier, J. A. and von Berckheim, C. Ph.: Measurement of
Atmospheric-Electric Field Strength and Air-Ion Concentration at Varying Distances From the Coast With a Mobile Measuring Station, Arch. Meteor. Geophy., 28, 107-109, 1979.

Eisele, F. L.: Direct troposheric ion sampling and mass identification, Int. J. Mass Spectrom. Ion Processes, 54, 119-126, 1983.

Eisele, F. L.: Natural and atmospheric negative ions in the troposphere, J. Geophys. Res., 94, 2183-2196, 1989a.

Eisele, F. L.: Natural and transmission line produced positive ions, J. Geophys. Res., 94, 6309-6318, 1989b.

Eisele, F. L. and McMurry, P. H.: Recent progress in understanding particle nucleation and growth, Philos. T. R. Soc. Lon. B, 352, 191-201, 1997.

Eisele, F. L., Lovejoy, E. R., Koscjuch, E., Moore, K. F., Mauldin III, R. L., Smith, J. N., McMurry, P. H., and Iida, K.: Negative atmospheric ion and their potential role in ion-induced nucleation, J. Geophys. Res., 111, D04305, doi:10.1020/2005JD006568, 2006.

Elster, J. and Geitel, H.: Über die Existenz elektrischer Ionen in der Atmosphäre, Terr. Magn. Atmos. Elect., 4, 213-234, 1899.

Enghoff, M. B. and Svensmark, H.: The role of atmospheric ions in aerosol nucleation-a review, Atmos. Chem. Phys., 8, 4911-4923, doi:10.5194/acp-8-4911-2008, 2008

Enghoff, M. B., Pedersen, J. O. P., Bondo, T., Johnson, M. S., Paling, S., and Svensmark, H.: Evidence for the Role of Ions in Aerosol Nucleation, J. Phys. Chem., 112, 10305-10309, 2008.

Erikson, H. A.: The change of mobility of the positive ions in air with age, Phys. Rev., 18, 100-101, 1921.

Faraday, M.: Experimental researches on electricity, 7th series, Phil. Trans. R. Soc. (Lond.), 124, 77-122, 1834.

Ferguson, E. E.: Sodium hydroxide ions in the stratosphere, Geophys. Res. Lett., 5, 1035-1038, 1978.

Fews, A. P., Holden, N. K., Keitch, P. A., and Henshaw, D. L.: A novel high-resolution small ion spectrometer to study ion nucleation of aerosols in ambient indoor and outdoor air, Atmos. Res., 76, 29-48, 2005.

Flagan, R. C.: History of Electrical Aerosol Measurements, Aerosol Sci. Tech., 28, 301-380, 1998.

Flagan, R. C.: Opposed Migration Aerosol Classifier (OMAC), Aerosol Sci. Tech., 38, 890-899, 2004.

Franchin, A., Siivola, E., Lehtipalo, K., Petäjä, T., and Kulmala, M.: Design and characterization of a double Gerdien ion counter, in Proceedings of the Finnish Center of Excellence and Graduate School in: Physics, Chemistry, Biology and Meteorology of Atmospheric Composition and Climate Change, annual workshop: 17-19 MAy 2010, edited by: Kulmala, M., Bäck, J.. and Nieminen, T., http://www.atm.helsinki.fi/FAAR/ reportseries/rs-109/abstracts.html, 2010.

Friedlander, S. K.: Smoke, Dust and Haze, Whiley, New York, 631 pp., 1977.

Froyd, K. D. and Lovejoy, E. R.: Experimental Thermodynamics of Cluster Ions Composed of $\mathrm{H}_{2} \mathrm{SO}_{4}$ and $\mathrm{H}_{2} \mathrm{O}, 1$. Positive Ions, J. Phys. Chem. A., 107, 9800-9811, 2003b.

Froyd, K. D. and Lovejoy, E. R.: Experimental Thermodynamics of Cluster Ions Composed of $\mathrm{H}_{2} \mathrm{SO}_{4}$ and $\mathrm{H}_{2} \mathrm{O}$. 2, measurements and ab Initio Structures of Negative Ions, J. Phys. Chem. A., 107, 9812-9824, 2003b.

Gagné, S., Laakso, L., Petäjä, T., Kerminen, V.-M., and Kulmala, M.: Analysis of one year of Ion-DMPS data from the SMEAR II station, Finland, Tellus, 60B, 318-329, 2008. 
Gagné, S., Nieminen, T., Kurtén, T., Manninen, H. E., Petäjä, T., Laakso, L., Kerminen, V.-M., and Kulmala, M.: Factors influencing the contribution of ion-induced nucleation in a boreal forest, Finland, Atmos. Chem. Phys., 10, 3743-3757, doi:10.5194/acp10-3743-2010, 2010.

Gagné, S., Lehtipalo, K., Manninen, H. E., Schobesberger, T., Franchin, A., Yli-Juuti, T., Bouloun, J., Sonntag, A., Mirme, S., Mirme, A., Hõrrak, U., Petäjä, T., Asmi, E., and Kulmala, M.: Intercomparison of air ion spectrometers: a basis for data interpretation, Atmos. Meas. Techniques., submitted, 2011.

Gerdien, H.: Die absolute Messung der elektrishen Leitfähigkeit und der spezifishen Iongeschwindigkeit in der Atmosphäre, Phys. Z., 4, 465-472, 1903.

Gerdien, H.: Demonstration eines apparates zur absolute Messung der elektrischen Leitfähigkeit der Luft, Phys. Z., 6, 800-801, 1905.

Gopalakrishnan, V., Pawar, S. D., Siingh, D., and Kamra, A. K.: Intermediate ion formation in the ship's exhaust, Geophys. Res. Lett., 32, L11806, doi:10.1029/2005GL022613, 2005.

Gupta, M., Chauhan, R. P., Garg, A., Kumar S., and Sonkawade, R.G.: Estimation of radioactivity in some sand and soil samples, Indian J. Pure Ap. Phy., 48, 482-485, 2010.

Hand, J. L. and Malm, W. C.: Review of aerosol mass scattering efficiencies from ground-based measurements since 1990, J. Geophys. Res., 112, D16203, doi:10.1029/2007JD008484, 2007.

Harrison, R. G. and Aplin, K. L.: Atmospheric condensation nuclei formation and high-energy radiation, J. Atmos. Sol.-Terr. Phy., 63, 1811-1819, 2001.

Harrison, R. G. and Aplin, K. L.: Water vapour changes and atmospheric cluster ions, Atmos. Res., 85, 199-208, 2007.

Harrison, R. G. and Carslaw, K. S.: Ion-aerosol-cloud processes in the lower atmosphere, Rev. Geophys., 41(3), 1012, doi:10.1029/2002RG000114, 2003.

Harrison, R. G. and Tammet, H.: Ions in Terrestrial Atmosphere and Other Solar System Atmospheres, Space Sci. Rev., 137, 107118, 2008.

Hatakka, J., Paatero, J., Viisanen, Y., and Mattsson, R.: Variations of external radiation due to meteorological and hydrological factors in central Finland, Radiochemistry, 40, 534-538, 1998.

Hatakka, J., Aalto, T., Aaltonen, V., Aurela, M., Hakola, H., Komppula, M., Laurela, T., Lihavainen, H., Paatero, J., Salminen, K., and Viisanen, Y.: Overview of the atmospheric research activities and results at Pallas GAW station, Boreal Environ. Res., 8, 365-383, 2003.

Haverkamp, H., Wilhelm, S., Sorokin, A., and Arnold, F.: Positive and negative ion measurements in jet aircraft engine exhaust: concentrations, sizes and implications for aerosol formation, Atmos. Environ., 38, 2879-2884, 2004.

Hensen, A., and van der Hage, J. C. H.: Parametrization of cosmic radiation at sea level, J. Geophys. Res., 99(D5), 10,693-10,695, 1994.

Hewitt, G. W.: The charging of small particles for electrostatic precipitation, Trans. AIEE Comm. Electr., 76, 300-306, 1957.

Hidy, G.M.: Aerosols. An Industrial and Environmental Science, Academic Press, Inc., London, 757 pp., 1984.

Hinds, W. C.: Aerosol technology: properties, behaviour, and measurement of airborne particles, Wiley, New York, USA,, 1999.

Hirsikko, A., Laakso, L, Hõrrak, U., Aalto, P. P., Kerminen, V.M., and Kulmala, M.: Annual and size dependent variation of growth rates and ion concentrations in boreal forest, Boreal Environ. Res., 10, 357-369, 2005.

Hirsikko, A., Bergmann, T., Laakso, L., Dal Maso, M., Riipinen, I., Hõrrak, U., and Kulmala, M.: Identification and classification of the formation of intermediate ions measured in boreal forest, Atmos. Chem. Phys., 7, 201-210, doi:10.5194/acp-7-201-2007, 2007a.

Hirsikko, A., Paatero, J., Hatakka, J., and Kulmala, M.: The ${ }^{222} \mathrm{Rn}$ activity concentration, external radiation dose and air ion production rates in a boreal forest in Finland between March 2000 and June 2006, Boreal Environ. Res., 12, 265-278, 2007 b.

Hirsikko, A., Yli-Juuti, T., Nieminen, T., Vartiainen, E., Laakso, L., Hussein, T., and Kulmala, M.: Indoor and outdoor air ions and aerosol particles in the urban atmosphere of Helsinki: characteristics, sources and formation, Boreal Environ. Res., 12, 295-310, 2007c.

Hogg, A. R.: The intermediate ions of the atmosphere, P. Phys. Soc. Lond., 51, 1014-1027, 1939.

Hoppel, W. A.: Ion-Aerosol Attachement Coefficients, Ion Depletion, and the Charge Distribution on Aerosols, J. Geophys. Res., 90, 5917-5923, 1985.

Hoppel, W. A. and Frick, G. M.: Ion-attachment coefficients and the steady-state charge distribution on aerosols in a bipolar ion environment, Aerosol Sci. Tech., 5, 1-21, 1986.

Hoppel, W. A. and Frick, G. M.: The nonequilibrium character of the aerosol charge distributions produced by neutralizers, Aerosol Sci. Tech., 12, 471-496, 1990.

Hõrrak, U.: Statistical results of air ions and aerosol measurements on the island of Vilsandi in the summer of 1984, Acta Comm. Univ. Tartu., 755, 47-57, 1987 (in Russian).

Hõrrak, U.: Air ion mobility spectrum at a rural area, in: Dissertationes Geophysicales Universitatis Tartuensis, 15, Tartu Univ. Press, Tartu, available at: http://ael.physic.ut.ee/KF.public/sci/ publs/UH_thesis/, 2001.

Hõrrak, U., Iher, H., Luts, A., Salm, J., and Tammet, H.: Mobility spectrum of air ions at Takhuse Observatory, J. Geophys. Res., 99, 10697-10700, 1994.

Hõrrak, U., Mirme, A., Salm, J., Tamm, E., and Tammet, H.: Air ion measurements as a source of information about atmospheric aerosols, Atmos. Res., 46, 233-242, 1998a.

Hõrrak, U., Salm, J., and Tammet, H.: Bursts of intermediate ions in atmospheric air, J. Geophys. Res., 103, 13909-13915, 1998 b.

Hõrrak, U., Salm, J., and Tammet, H.: Statistical characterization of air ion mobility spectra at Tahkuse Observatory: Classification of air ions, J. Geophys. Res., 105, 9291-9302, 2000.

Hõrrak, U., Salm, J., and Tammet, H.: Diurnal variation in the concentration of air ions of different mobility classes in a rural area, J. Geophys. Res., 108(D20), 4653, doi:10.1029/2002JD003240, 2003.

Hõrrak, U., Tammet, H., Aalto, P. P., Vana, M., Hirsikko, A., Laakso, L., and Kulmala, M.: Formation of charged particles associated with rainfall: atmospheric measurements and lab experiments, Rep. Ser. Aerosol Sci., 80, 180-185, 2006.

Hõrrak, U., Aalto, P. P., Salm, J., Komsaare, K., Tammet, H., Mäkelä, J. M., Laakso, L., and Kulmala, M.: Variation and balance of positive air ion concentrations in a boreal forest, Atmos. Chem. Phys., 8, 655-675, doi:10.5194/acp-8-655-2008, 2008.

Hurd, F. K. and Mullins, J. C.: Aerosol Size Distributions from Ion Mobility, J. Colloid Interf. Sci., 17, 91-100, 1962. 
Hussein, T., Dal Maso, M., Petäjä, T., Koponen, I. K., Paatero, P., Aalto, P. P., Hämeri, K., and Kulmala, M.: Evaluation of an automatic algorithm for fitting the particle number size distributions, Boreal Environ. Res., 10, 337-355, 2005.

Iida, K., Stolzenburg, M., McMurry, P., Dunn, M. J., Smith, J. N., Eisele, F., and Keady, P.: Contribution of ion-induced nucleation to new particle formation: Methodology and its application to atmospheric observations in Boulder, Colorado, J. Geophys. Res., 111, D23201, doi:10.1029/2006JD007167, 2006.

Iida, K., Stolzenburg, M. R., McMurry, P. H., and Smith, J. N.: Estimating nanoparticle growth rates from sizedependent charged fractions: Analysis of new particle formation events in Mexico City, J. Geophys. Res., 113, D05207, doi:10.1029/2007JD009260, 2008.

Iida, K., Stolzenburg, M. R., and McMurry, P. H.: Effect of Working Fluid on Sub-2 nm Particle Detection with a Laminar Flow Ultrafine Condensation Particle Counter, Aerosol Sci. Tech., 43(1), 81-96, 2009.

Ilic, R., Rusov, V. D., Pavlovych, V. N., Vaschenko, V. M., Hanzic, L., and Bondarchuk, Y. A.: Radon in Antarctica, Radiat. Meas., 40, 415-422, 2005.

Israël, H.: Ein transportables Messgerät für schwere Ionen, Z. Geophys., 5, 342-350, 1929.

Israël, H.: Zur Theorie und Methodik der Grössenbestimmung von Luftionen, Gerlands Beitr. Geophys., 31, 173-216, 1931.

Israël, H.: Atmospheric Electricity, Israel Program for Scientific Translations, Jerusalem, 1, 317 pp., 1970.

Israel, H. and Schulz, L.: The mobility-spectrum of atmospheric ions-principles of measurements and results, Terr. Magn., 38, 285-300, 1933.

Israelsson, S. and Knudsen, E.: Effects of radioactive fallout from a nuclear power plant accident on electrical parameters, J. Geophys. Res., 91(D11), 11909-11910, 1986.

Jayaratne, E. R., Ling, X., and Morawska, L.: Ions in motor vehicle exhaust and their dispersion near busy roads, Atmos. Environ., 44, 3644-3650, 2010.

Jiang, J., Zhao, J., Chen, M., Eisele, F.L., Scheckman, J., Williams, B.J., Kuang, C., and McMurry, P.H.: First Measurements of Neutral Atmospheric Cluster and 1-2 nm Particle Number Size Distributions During Nucleation Events, Aerosol Sci. Technol. (Aerosol Research Letter), 45, 4, ii-v, $2011 \mathrm{a}$.

Jiang, J., Chen, M., Kuang, C., Attoui, M., and McMurry, P. H.: Electrical Mobility Spectrometer Using a Diethylene Glycol Condensation Particle Counter for Measurements of Aerosol Size Distributions Down to $1 \mathrm{~nm}$, Aerosol Sci. Technol., 45, 4, 510-521, 2011b.

Junninen, H., Hulkkonen, M., Riipinen, I., Nieminen, T., Hirsikko, A., Suni, T., Boy, M., Lee, S.-H., Vana, M., Tammet, H., Kerminen, V.-M., and Kulmala M.: Observations on nocturnal growth of atmospheric clusters, Tellus, 60B, 365-371, 2008.

Junninen, H., Ehn, M., Petäjä, T., Luosujärvi, L., Kotiaho, T., Kostiainen, R., Roghner, U., Gonin, M., Fuhrer, K., Kulmala, M., and Worsnop, D. R.: A high-resolution mass spectrometer to measure atmospheric ion composition, Atmos. Meas. Tech., 3, 1039-1053, doi:10.5194/amt-3-1039-2010, 2010.

Kamra, A. K., Siingh, D., and Pant, V.: Scavenging of atmospheric ions and aerosol by drifting snow in Antarctica, Atmos. Res., 91, 215-218, 2009.

Kazil, J., Harrison, R. G., and Lovejoy, E. R.: Tropospheric New
Particle Formation and the Role of Ions, Space Sci. Rev., 137, 241-255, 2008.

Kazil, J., Stier, P., Zhang, K., Quaas, J., Kinne, S., O’Donnell, D., Rast, S., Esch, M., Ferrachat, S., Lohmann, U., and Feichter, J.: Aerosol nucleation and its role for clouds and Earth's radiative forcing in the aerosol-climate model ECHAM5-HAM, Atmos. Chem. Phys., 10, 10733-10752, doi:10.5194/acp-1010733-2010, 2010.

Kanawade, V. and Tripathi, S. N.: Evidence for the role of ion-induced particle formation during an atmospheric nucleation event observed in Tropospheric Ozone Production about the Spring Equinox (TOPSE), J. Geophys. Res., 111, D02209, doi:10.1029/2005JD006366, 2006.

Keesee, R. G. and Castleman Jr., A. W.: Ions and cluster ions: Experimental studies and atmospheric observations, J. Geophys. Res., 90, 5885-45890, 1985.

Kerminen, V.-M., Anttila, T., Petäjä, T., Laakso, L., Gagné, S., Lehtinen, K. E. J., and Kulmala, M.: Charging state of the atmospheric nucleation mode: Implications for separating neutral and ion-induced nucleation, J. Geophys. Res., 112, D21205, doi:10.1029/2007JD008649, 2007.

Kerminen, V.-M., Petäjä, T., Manninen, H. E., Paasonen, P., Nieminen, T., Sipilä, M., Junninen, H., Ehn, M., Gagné, S., Laakso, L., Riipinen, I., Vehkamäki, H., Kurten, T., Ortega, I. K., Dal Maso, M., Brus, D., Hyvärinen, A., Lihavainen, H., Leppä, J., Lehtinen, K. E. J., Mirme, A., Mirme, S., Hõrrak, U., Berndt, T., Stratmann, F., Birmili, W., Wiedensohler, A., Metzger, A., Dommen, J., Baltensperger, U., Kiendler-Scharr, A., Mentel, T. F., Wildt, J., Winkler, P. M., Wagner, P. E., Petzold, A., Minikin, A., Plass-Dlmer, C., Pöschl, U., Laaksonen, A., and Kulmala, M.: Atmospheric nucleation: highlights of the EUCAARI project and future directions, Atmos. Chem. Phys., 10, 10829-10848, doi:10.5194/acp-10-10829-2010, 2010.

Kirkby, J.: Cosmic rays and climate, Surv. Geophys., 28, 333-375, 2008.

Knutson, E. O. and Whitby, K. T.: Accurate measurement of aerosol electric mobility moments, J. Aerosol Sci., 6, 443-451, 1975.

Komppula, M., Vana, M., Kerminen, V.-M., Lihavainen, H., Viisanen, Y., Hõrrak, U., Komsaare, K., Tamm, E., Hirsikko, A., Laakso, L., and Kulmala, M.: Size distributions of atmospheric ions in the Baltic Sea region, Boreal Environ. Res., 12, 323-336, 2007.

Ku, B. K. and de la Mora, J. F.: Relation between Electrical Mobility, Mass, and Size for Nanodrops 1-6.5 nm in Diameter in Air, Aerosol Sci. Tech., 43, 241-249, 2009.

Kuang, C., McMurry, P. H., McCormick, A. V., and Eisele, F. L.: Dependence of nucleation rates on sulphuric acid vapor concentration in diverse atmospheric locations, J. Geophys. Res.Atmos, 113(D10), D10209, doi:10.1029/2007JD009253, 2008.

Kulmala, M. and Kerminen, V.-M.: On the formation and growth of atmospheric nanoparticles, Atmos. Res., 90, 132-150, 2008.

Kulmala, M. and Tammet, H.: Finnish-Estonian air ion and aerosol workshops, Boreal Environ. Res., 12, 237-245, 2007.

Kulmala, M., Dal Maso, M., Mäkelä, J.M., Pirjola, L., Väkevä, M., Aalto, P., Miikkulainen, P., Hämeri, K. and O'Dowd, C.: On the formation, growth and composition of nucleation mode particles, Tellus B, 53, 479-490, 2001.

Kulmala, M., Hari, P., Laaksonen, A., Vesala, T., and Viisanen, Y.: Research Unit of Physics, Chemistry and Biology of 
Atmospheric Composition and Climate Change: overview of recent results, Boreal Env. Res., 10, 459-477, 2005.

Kulmala, M., Lehtinen, K. E. J., and Laaksonen, A.: Cluster activation theory as an explanation of the linear dependence between formation rate of $3 \mathrm{~nm}$ particles and sulphuric acid concentration, Atmos. Chem. Phys., 6, 787-793, doi:10.5194/acp-6-787-2006, 2006.

Kulmala, M., Vehkamäki, H., Petäjä, T., Dal Maso, M., Lauri, A., Kerminen, V.-M., Birmili, W., and McMurry, P. H.: Formation and growth rates of ultrafine atmospheric particles: a review of observations, J. Aerosol Sci., 35, 143-176, 2004a.

Kulmala, M., Laakso, L., Lehtinen, K. E. J., Riipinen, I., Dal Maso, M., Anttila, T., Kerminen, V.-M., Hõrral, U., Vana, M., and Tammet, H.: Initial steps of aerosol growth, Atmos. Chem. Phys., 4, 2553-2560, doi:10.5194/acp-4-2553-2004, 2004b.

Kulmala, M., Riipinen, I., Sipilä, M., Manninen, H. E., Petäjä, T., Junninen, H., Dal Maso, M., Mordas, G., Mirme, A., Vana, M., Hirsikko, A., Laakso, L., Harrison, R. M., Hanson, I., Leung, C., Lehtinen, K. E. J., and Kerminen, V.-M.: Toward direct measurement of atmospheric nucleation, Science, 318, 89-92, 2007.

Kulmala, M., Riipinen, I., Nieminen, T., Hulkkonen, M., Sogacheva, L., Manninen, H. E., Paasonen, P., Petj, T., Dal Maso, M., Aalto, P. P., Viljanen, A., Usoskin, I., Vainio, R., Mirme, S., Mirme, A., Minikin, A., Petzold, A., Hrrak, U., Pla-Dlmer, C., Birmili, W., and Kerminen, V.-M.: Atmospheric data over a solar cycle: no connection between galactic cosmic rays and new particle formation, Atmos. Chem. Phys., 10, 1885-1898, doi:10.5194/acp-10-1885-2010, 2010.

Laakso, L., Mäkelä, J. M., Pirjola, L., and Kulmala, M.: Model studies on ion-induced nucleation in the atmosphere, J. Geophys. Res., 107(D20), 4427, doi:10.1029/2002JD002140, 2002.

Laakso, L., Petäjä, T., Lehtinen, K. E. J., Kulmala, M., Paatero, J., Hõrrak, U., Tammet, H., and Joutsensaari, J.: Ion production rate in a boreal forest based on ion, particle and radiation measurements, Atmos. Chem. Phys., 4, 1933-1943, doi:10.5194/acp-41933-2004, 2004a.

Laakso, L., Anttila, T., Lehtinen, K. E. J., Aalto, P. P., Kulmala, M., Hõrrak, U., Paatero, J., Hanke, M., and Arnold, F.: Kinetic nucleation and ions in boreal forest particle formation events, Atmos. Chem. Phys., 4, 2353-2366, doi:10.5194/acp-4-2353-2004, 2004b.

Laakso, L., Gagné, S., Petäjä, T., Hirsikko, A., Aalto, P. P., Kulmala, M., and Kerminen, V.-M.: Detecting charging state of ultra-fine particles: instrumental development and ambient measurement, Atmos. Chem. Phys., 7, 1333-1345, doi:10.5194/acp-7-13332007, 2007a.

Laakso, L., Hirsikko, A., Grönholm, T., Kulmala, M., Luts, A., and Parts, T.-E.: Waterfalls as sources of small charged aerosol particles, Atmos. Chem. Phys., 7, 2271-2275, doi:10.5194/acp-72271-2007, 2007b.

Laakso, L., Grönholm, T., Kulmala, L., Haapanala, S., Hirsikko, A., Lovejoy, E. R., Kazil, J., Kurtén, T., Boy, M., Nilsson, E. D., Sogachev, A., Riipinen, I., Stratmann, F., and Kulmala, M.: Hotair balloon as a platform for boundary layer profile measurements during particle formation, Boreal Environ. Res., 12, 279-294, $2007 \mathrm{c}$.

Laakso, L., Laakso, H., Aalto, P. P., Keronen, P., Petäjä, T., Nieminen, T., Pohja, T., Siivola, E., Kulmala, M., Kgabi, N., Molefe, M., Mabaso, D., Phalatse, D., Pienaar, K., and Kerminen, V.-M.:
Basic characteristics of atmospheric particles trace gases and meteorology in a relatively clean Southern African Savannah environment, Atmos. Chem. Phys., 8, 4823-4839, doi:10.5194/acp8-4823-2008, 2008.

Larriba, C., Hogan, C. J., Attoui, M., Barrajo, R., FernandezGarcia, J., and Fernandez de la Mora, J.; The Mobility-Volume Relationship below $3.0 \mathrm{~nm}$ Examined by Tandem Mobility-Mass Measurement, Aerosol Sci. Tech., 45, 4, 453-467, 2011.

Langevin, P.: Sur les ions de l'atmosphère, C. R. Acad. Sci., 140, 232-234, 1905.

Lee, S.-H., Reeves, J. M., Wilson, J. C., Hunton, D. E., Viggiano, A. A., Miller, T. M., Ballenthin, J. O., and Lait, L. R.: Particle formation by ion nucleation in the upper troposphere and lower stratosphere, Science, 301, 1886-1889, 2003.

Lee, S.-H., Young, L.-H., Benson, D. R., Suni, T., Kulmala, M., Junninen, H., Campos, T. L., Rogers, D. C., and Jensen, J.: Observations of nighttime new particle formation in the troposphere, J. Geophys. Res., 113, D10210, doi:10.1029/2007JD009351, 2008.

Lehtinen, K. E. J. and Kulmala, M.: A model for particle formation and growth in the atmosphere with molecular resolution in size, Atmos. Chem. Phys., 3, 251-258, doi:10.5194/acp-3-251-2003, 2003.

Lehtipalo, K., Sipilä, M., Riipinen, I., Nieminen, T., and Kulmala, M.: Analysis of atmospheric neutral and charged molecular clusters in boreal forest using pulse-height CPC, Atmos. Chem. Phys., 9, 4177-4184, doi:10.5194/acp-9-4177-2009, 2009.

Lehtipalo, K., Sipilä, M., Junninen, H., Ehn, M., Berndt, T., Kajos, M. K., Worsnop, D. R., Petäjä, T., and Kulmala, M.: Observations of Nano-CN in the Nocturnal Boreal Forest, Aerosol Sci. Technol., 45, 4, 499-509, 2011.

Lehtipalo, K., Kulmala, M., Sipilä, M., Petäjä, T., Vana, M., Ceburnis, D., Dupuy, R., and O'Dowd, C.: Nanoparticles in boreal forest and coastal environment: a comparison of observations and implications of the nucleation mechanism, Atmos. Chem. Phys., 10, 7009-7016, doi:10.5194/acp-10-7009-2010, 2010.

Leppä, J., Kerminen, V.-M., Laakso, L., Korhonen, H., Lehtinen, K. E. J., Gagne, S., Manninen, H. E., Nieminen, T., and Kulmala, M.: Ion-UHMA: a model for simulating the dynamics of neutral and charged aerosol particles, Boreal Environ. Res., 14, 559$575,2009$.

Li, Z. and Wang, H.: Drag force, diffusion coefficient, and electric mobility of small particles. I. Theory applicable to the free-molecule regime, Phys. Rev. E, 68, 061206, doi:10.1103/PhysRevE.68.061206, 2003.

Lihavainen, H., Komppula, M., Kerminen, V.-M., Järvinen, H., Viisanen, Y., Lehtinen, K., Vana, M., and Kulmala, M.: Size distributions of atmospheric ions inside clouds and in cloud-free air at a remote continental site, Boreal Environ. Res., 12, 337-344, 2007.

Ling, X., Jayaratne, R., and Morawska, L.: Air ion concentrations in various urban outdoor environments, Atmos. Environ., 44, 2186 2193, 2010.

Liu, B. Y. H. and Pui, D. Y. H.: A submicron aerosol standard and the primary, absolute calibration of the condensation nuclei counter, J. Colloid Interface Sci., 47, 155-171, 1974.

Loscertales, I. G.: Drift differential mobility analyzer, J. Aerosol Sci. 29, 1117-1139, 1998.

Luts, A. and Parts, T.-E.: Evolution of negative small air ions at two 
different temperatures, J. Atmos. Sol.-Terr. Phys., 64, 763-774, 2002.

Lähde, T., Rönkkö, T., Virtanen, A., Schuck, T. J., Pirjola, L., Hämeri, K., Kulmala, M., Arnold, F., Rothe, D., and Keskinen, J.: Heavy Duty Diesel Engine Exhaust Aerosol Particle and Ion Measurements, Environ. Sci. Tech., 43, 163-168, 2009.

Manninen, H. E., Petäjä, T., Asmi, E., Riipinen, I., Nieminen, T., Mikkilä, J., Hõrrak, U., Mirme, A., Mirme, S., Laakso, L., Kerminen, V.-M., and Kulmala, M.: Long-term field measurements of charged and neutral clusters using Neutral cluster and Air Ion Spectrometer (NAIS), Boreal Environ. Res., 14, 591-605, 2009a.

Manninen, H. E., Nieminen, T., Riipinen, I., Yli-Juuti, T., Gagné, S., Asmi, E., Aalto, P. P., Petäjä, T., Kerminen, V.-M., and Kulmala, M.: Charged and total particle formation and growth rates during EUCAARI 2007 campaign in Hyytiälä, Atmos. Chem. Phys., 9, 4077-4089, doi:10.5194/acp-9-4077-2009, 2009b.

Manninen, H. E., Nieminen, T., Asmi, E., Gagné, S., Häkkinen, S., Lehtipalo, K., Aalto, P., Vana, M., Mirme, A., Mirme, S., Hõrrak, U., Plass-Dülmer, C., Stange, G., Kiss, G., Hoffer, A., Töro, N., Moerman, M., Henzing, B., de Leeuw, G., Brinkenberg, M., Kouvarakis, G. N., Bougiatioti, A., Mihalopoulos, N., O’Dowd, C., Ceburnis, D., Arneth, A., Svenningsson, B., Swietlicki, E., Tarozzi, L., Decesari, S., Facchini, M.C., Birmili, W., Sonntag, A., Wiedensohler, A., Boulon, J., Sellegri, K., Laj, P., Gysel, M., Bukowiecki, N., Weingartner, E., Wehrle, G., Laaksonen, A., Hamed, A., Joutsensaari, J., Petäjä, T., Kerminen, V.-M., and Kulmala, M.: EUCAARI ion spectrometer measurements at 12 European sites - analysis of new-particle formation events, Atmos. Chem. Phys., 10, 7907-7927, doi:10.5194/acp-10-79072010, 2010.

Matisen, R., Miller, F., Tammet, H., and Salm, J.: Air ion counters and spectrometers designed in Tartu University, Acta Comm. Univ. Tartu., 947, 60-67, 1992.

McClelland, J. A.: On the conductivity of hot gases from flames, Philos. Mag., 46, 29-42, 1898.

Mehra, R., Singh, S., and Singh, K.: Analysis of 226 Ra, 232 Th and $40 \mathrm{~K}$ in soil samples for the assessment of the average effective dose, Indian J. Phys., 83, 1031-1037, 2009.

Millikan, R. A.: The general law of fall of a small spherical body through a gas, and its bearing upon the nature of molecular reflection from surfaces, Phys. Rev., 22, 1-23, 1923.

Mirme, A., Tamm, E., Mordas, G., Vana, M., Uin, J., Mirme, S., Bernotas, T., Laakso, L., Hirsikko, A., and Kulmala, M.: A widerange multi-channel Air Ion Spectrometer, Boreal Environ. Res., 12, 247-264, 2007.

Mirme, S., Mirme, A., Minikin, A., Petzold, A., Hõrrak, U., Kerminen, V.-M., and Kulmala, M.: Atmospheric sub-3nm particles at high altitudes, Atmos. Chem. Phys., 10, 437-451, doi:10.5194/acp-10-437-2010, 2010.

Misaki, M.: A Method of Measuring the Ion Spectrum, Pap. Meteorol. Geophys., 1, 313-318, 1950.

Misaki, M.: Studies on the Atmospheric ion Spectrum (I). Procedures of experimental and data analysis, Pap. Meteorol. Geophys., 12, 247-260, 1961a.

Misaki, M.: Studies on the Atmospheric Ion Spectrum (II). Relation between the ion spectrum and the electrical conductivity, Pap. Meteorol. Geophys., 12, 261-276, 1961b.

Misaki, M., Ohtagaki, M., and Kanazawa, I.: Mobility spectrometry of the atmospheric pollution, Pure Appl. Geophys., 100, 133-
145, 1972a.

Misaki, M., Ikegami, M., and Kanazawa, I.: Atmospheric electrical conductivity measurement in the Pasific Ocean, exploring the background level of global pollution, J. Meteorol. Soc. Japan, 50, 497-500, 1972b.

Misaki, M., Ikegami, M., and Kanazawa, I.: Deformation of the size distribution of aerosol particles dispersing from land to ocean, J. Meteorol. Soc. Japan, 53, 111-120, 1975.

Mohnen, V. A.: Formation, nature and mobility of ions of atmospheric importance, in: Electrical Processes in Atmospheres, edited by: Dolezalek, H. and Reiter, R., Dr. Dietrich Steinkopff Verlag, Darmstadt, Germany, 1-17, 1977.

Modini, R. L., Ristovski, Z. D., Johnson, G. R., He, C., Surawski, N., Morawska, L., Suni, T., and Kulmala, M.: New particle formation and growth at a remote, sub-tropical coastal location, Atmos. Chem. Phys., 9, 7607-7621, doi:10.5194/acp-9-7607-2009, 2009.

Myhre, G.: Consistency between satellite-derived and modelled estimates of the direct aerosol effect, Science, 325, 187-190, 2009.

Myles, L. T., Meyers, T. P., and Robinson, L.: Atmospheric ammonia measurement with an ion mobility spectrometer, Atmos. Environ., 40, 5745-5752, 2006.

Mäkelä, J.M., Riihelä, M., Ukkonen, A., Jokinen, V., and Keskinen, J.: Comparison of mobility equivalent with Kelvin-Thomson diameter using ion mobility data, J. Chem. Phys., 105, 1562-1571, 1996.

Nadykto, A. B. and Yu, F.: Formation of binary ion clusters from polar vapours: effect of the dipole-charge interaction, Atmos. Chem. Phys., 4, 385-389, doi:10.5194/acp-4-385-2004, 2004.

Nagaraja, K., Prasad, B. S. N., Madhava, M. S., and Paramesh, L.: Concentration of radon and its progeny near the surface of the earth at a continental station Pune $\left(18^{\circ} \mathrm{N}, 74^{\circ} \mathrm{E}\right)$, Ind. J. Pure Ap. Phys., 41, 562-569, 2003.

Nagato, K. and Ogawa, T.: Evolution of tropospheric ions observed by an ion mobility spectrometer with a drift tube, J. Geophys. Res., 103, 13917-13925, 1998.

Nagato, K., Tanner, D. J., Friedli, H.R., and Eisele, F.L.: Field measurement of positivie ion mobility and mass spectra at a Colorado site in winter, J. Geophys. Res., 104, 3471-3482, 1999.

Nieminen, T., Manninen, H. E., Sihto, S.-L., Yli-Juuti, T., Mauldin, I. L., III., Petäjä, T., Riipinen, I., Kerminen, V.-M., and Kulmala, M.: Connection of Sulphuric Acid to Atmospheric Nucleation in Boreal Forest, Environ. Sci. Technol., 43, 4715-4721, 2009.

Nolan, J. J. and de Sachy, G. P.: Atmospheric ionization, P. Roy. Irish Acad., A37, 71-94, 1927.

Norinder, H. and Siksna, R.: Variations in the density of small ions caused by the accumulation of emanation exhaled from the soil, Tellus, 2, 168-172, 1950.

Ogawa, T.: Fair-weather electricity, J. Geophys. Res., 90, 59515960, 1985.

Paasonen, P., Sihto, S.-L., Nieminen, T., Vuollekoski, H., Riipinen, I., Pla $\beta$-Dülmer, C., Berresheim, H., Birmili, W., and Kulmala, M.: Connection between new particle formation and sulphuric acid at Hohenpeissenberg (Germany) including the influence of organic compounds, Boreal Environ. Res., 14, 616-629, 2009.

Paasonen, P., Nieminen, T., Asmi, E., Manninen, H., Petäjä, T., Plass-Dülner, C., Birmili, W., Hõrrak, U., Metzger, A., Baltensperger, U., Hamed, A., Laaksonen, A., Kerminen, V.-M., and Kulmala, M.: On the role of sulphuric acid and low- 
volatility organic vapours in new particle formation at four European measurement sites, Atmos. Chem. Phys., 10, 11223-11242, doi:10.5194/acp-10-11223-2010, 2010.

Parts, T.-E. and Luts, A.: Observed and simulated effects of certain pollutants on small air ion spectra: I. Positive ions, Atmos. Environ., 38(9), 1283-1289, 2004.

Pawar, S. D., Siingh, D., Gopalakrishnan, V., and Kamra, A. K.: Effect of the onset of southwest monsoon on the atmospheric electric conductivity over the Arabian Sea, J. Geophys. Res., 110, D10204, doi:10.1029/2004JD005689, 2005.

Pedersen, C. S., Lauritsen, F. R., Sysoev, A., Viitanen, A.-K., Mäkelä, J. M., Adamov, A., Laakia, J., Mauriala, T., and Kotiaho, T.: Characterazation of Proton-Bound Acetate Dimers in Ion Mobility Spectrometry, J. Am. Soc. Mass Spectr., 19, 13611366, 2008.

Pollock, J. A.: A new type of ion in the air, Philos. Mag., 29, 636646, 1915.

Prüller, P. and Saks, O.: Ion counter with automatic photorecorder and vibrating-reed electrometer, Acta Comm. Univ. Tartu., 240, 32-60, 1970.

Quaas, J., Ming, Y., Menon, S., Takemura, T., Wang, M., Penner, J.E., Gettelman, A., Lohmann, U., Bellouin, N., Boucher, O., Sayer, A.M., Thomas, G.E., McComiskey, A., Feingold, G., Hoose, C., Kristjánsson, J.E., Liu, X., Balkanski, Y., Donner, L. J., Ginoux, P.A., Stier, P., Grandey, B., Feichter, J., Sednev, I., Bauer, S.E., Koch, D., Grainger, R.G., Kirkevåg, A., Iversen, T., Seland, Ø., Easter, R., Ghan, S.J., Rasch, P.J., Morrison, H., Lamarque, J.-F., Iacono, M. J., Kinne, S., and Schulz, M.: Aerosol indirect effects - general circulation mode intercomparison and evaluation with satellite data, Atmos. Chem. Phys., 9, 8697-8717, doi:10.5194/acp-9-8697-2009, 2009.

Reinet, J.: A combined counter of atmospheric ions (Russian), Tr. Main Geophys. Observ., 58, 23-30, 1956.

Reinet, J.: On the changes of atmospheric ionization in Tartu during a yearly period (Estonian), Acta Comm. Univ. Tartu., 59, 71107, 1958.

Reiter, R.: Frequency distribution of positive and negative small ion concentrations, based on many years' recordings at two mountain stations located at 740 and $1780 \mathrm{~m}$ a.s.l., Int. J. Biometeorol., 29, 223-231, 1985.

Retalis, D. A.: On the Relationship Between Small Atmospheric Ions Concentration and (1) Smoke, (2) Sulfur Dioxide and (3) Wind Speed, Pure Appl. Geophys., 115, 575-581, 1977.

Retalis, D. and Pitta, A.: Effects of electrical parameters at Athens Greece by radioactive fallout from a nuclear power plant accident, J. Geophys. Res., 94(D11), 13093-13097, 1989.

Retalis, A., Nastos, P., and Retalis, D.: Study of small ions concentration in the air above Athens, Greece, Atmos. Res., 91, 219228, 2009.

Richmann, G. W.: De electricitate in corporibus producenda nova tentamina, Commentarii Acad. Sci. Imper. Petropolitanae., 14, 299-326, 1744-1746, 1751.

Richmann, G. W.: Trudy po fizike (translations into Russian), edited by: Eliseev, A. A., Zubov, V. P., and Murzin, A. M., Akad. Nauk. SSSR, Moscow, 1956.

Riecke, E.: Beiträge zu der Lehre von der Luftelektrizität, Ann. Phys., 12, 52-84, 1903.

Riipinen, I., Sihto, S.-L., Kulmala, M., Arnold, F., Dal Maso, M., Birmili, W., Saarnio, K., Teinilä, K., Kerminen, V.-M., Laak- sonen, A., and Lehtinen, K. E. J.: Connections between atmospheric sulphuric acid and new particle formation during QUEST III-IV campaigns in Heidelberg and Hyytiälä, Atmos. Chem. Phys., 7, 1899-1914, doi:10.5194/acp-7-1899-2007, 2007.

Riipinen, I., Manninen, H.E., Yli-Juuti, T., Boy, M., Sipilä, M., Ehn, M., Junninen, H., Petäjä, T., and Kulmala, M.: Applying the Condensation Particle Counter Battery (CPCB) to study the water-affinity of freshly-formed 2-9 nm particles in boreal forest, Atmos. Chem. Phys., 9, 3317-3330, doi:10.5194/acp-9-33172009, 2009.

Ristovski, Z. D., Suni, T., Kulmala, M., Boy M., Meyer, N. K., Duplissy, J., Turnipseed, A., Morawska, L., and Baltensperger, U.: The role of sulphates and organic vapours in growth of newly formed particles in a eucalypt forest, Atmos. Chem. Phys., 10, 2919-2926, doi:10.5194/acp-10-2919-2010, 2010.

Robertson, L. B., Stevenson, D. S., and Conen, F.: Test of a northwards-decreasing ${ }^{222} \mathrm{Rn}$ source term by comparison of modelled and observed atmospheric ${ }^{222} \mathrm{Rn}$ concentrations, Tellus, 57B, 116-123, 2005.

Rosen, J. M., Hofmann, D. J., and Gringel, W.: Measurements of ion mobility to $30 \mathrm{~km}$, J. Geophys. Res., 90, 5876-5884, 1985.

Russell, A. G. and Brunekreef, B.: A focus on particulate matter and health, Environ. Sci. Tech., 43, 4620-4625, 2009.

Ruuskanen, T. M., Kaasik, M., Aalto, P. P., Hõrrak, U., Vana, M., Mårtensson, M., Yoon, Y. J., Keronen, P., Mordas, G., Ceburnis, D., Nilsson, E. D., O’Dowd, C., Noppel, M., Alliksaar, T., Ivask, J., Sofiev, M., Prank, M., and Kulmala, M.: Concentrations and fluxes of aerosol particles during the LAPBIAT measurement campaign at Värriö field station, Atmos. Chem. Phys., 7, 3683-3700, doi:10.5194/acp-7-3683-2007, 2007.

Rutherford, E.: The velocity and rate of recombination of the ions of gases exposed to Rontgen radiation, Philos. Mag., 44, 422440, 1897.

Salm, J., Tammet, H., Iher, H., and Hõrrak, U.: The dependence of small air ion mobility spectra in the ground layer of the atmosphere on temperature and pressure, Acta Comm. Univ. Tartu., 947, 50-56, 1992.

Saros, M., Weber, R. J., Marti, J., and McMurry, P. H.: Ultra fine aerosol measurement using a condensation nucleus counter with pulse height analysis, Aerosol Sci. Tech., 25, 200-213, 1996.

Seinfeld, J. H. and Pandis, S. N.: Atmospheric chemistry and physics: From air pollution to climate change, John Wiley \& Sons, Inc., New York, USA, 1998.

Sgro, L. A. and Fernandez de la Mora, J.: A Simple Turbulent Mixing CNC for Charged Particle Detection Down to $1.2 \mathrm{~nm}$, Aerosol Sci. Tech., 38, 1-11, 2004.

Shashikumar, T. S., Ragini, N., Chandrashekara, M. S., and Paramesh, L.: Studies on radon in soil, its concentration in the atmosphere and gamma exposure rate around Mysore city, India, Curr. Sci., 94, 1180-1185, 2008.

Sihto, S.-L., Kulmala, M., Kerminen, V.-M., Dal Maso, M., Petäjä, T., Riipinen, I., Korhonen, H., Arnold, F., Janson, R., Boy, M., Laaksonen, A., and Lehtinen, K. E. J.: Atmospheric sulphuric acid and aerosol formation: implications from atmospheric measurements for nucleation and early growth mechanisms, Atmos. Chem. Phys., 6, 4079-4091, doi:10.5194/acp-6-4079-2006, 2006.

Siingh, D., Pawar, S. D., Gopalakrishnan, V., and Kamra, A. K.: Measurements of the ion concentrations and conductivity over 
the Arabian Sea during ARMEX, J. Geophys. Res., 110, D18207, doi:10.1029/2005JD005765, 2005.

Siingh, D., Pant, V., and Kamra, A. K.: Measurements of positive ions and air-Earth current density at Maitri, Antarctica, J. Geophys. Res., 112, D13212, doi:10.1029/2006JD008101, 2007.

Siksna, R.: Variations of large-ions in atmospheric air during disturbed weather conditions, Arkiv Geofys., 1, 237-246, 1950.

Sipilä, M., Lehtipalo, K., Kulmala, M., Petäjä, T., Junninen, H., Aalto, P.P., Manninen, H. E., Kyrö, E.-M., Asmi, E., Riipinen, I., Curtius, J., Kürten, A., Borrmann, S., and O'Dowd, C. D.: Applicability of condensation particle counters to measure atmospheric clusters, Atmos. Chem. Phys., 8, 4049-4060, doi:10.5194/acp-8-4049-2008, 2008.

Sipilä, M., Lehtipalo, K., Attoui, M., Neitola, K., Petäjä, T., Aalto, P. P., O'Dowd, C. D., and Kulmala, M.: Laboratory Verification of PH-CPC's Ability to Monitor Atmospheric Sub-3 nm Clusters, Aerosol Sci. Tech., 43, 126-135, 2009.

Sipilä, M., Berndt, T., Petäjä, T., Brus, D., Vanhanen, J., Stratmann, F., Patokoski, J., Mauldin, III R.L., Hyvärinen, A.-P., Lihavainen, H., and Kulmala, M.: The Role of Sulfuric Acid in Atmospheric Nucleation, Science, 5, 1243-1246, 2010.

Smirnov, V. V.: Nature and Evolution of Ultrafine Aerosol Particles in the Atmosphere, Izv. Atmos. Ocean. Phys., 42, 663-687, 2006

Smirnov, V. V., Radionov, V. F., Savchenko, A. V., Pronin, A. A., and Kuusk, V. V.: Variability in aerosol and air ion composition in the Arctic spring atmosphere, Atmos. Res., 49, 163-176, 1998.

Smith, J. N., Moore, K. F., Eisele, F. L., Voisin, D., Ghimire, A. K., Sakurai, H., and McMurry, P. H.: Chemical composition of atmospheric nanoparticles during nucleation events in Atlanta, J. Geophys. Res., 110, D22S03, doi:10.1029/2005JD005912, 2005

Smith, J. N., Dunn, M. J., VanReken, T. M., Iida, K., Stolzenburg, M. R., McMurry, P. H., and Huye, L. G.: Chemical composition of atmospheric nanoparticles formed from nucleation in Tecamac, Mexico: Evidence for an important role for organic species in nanoparticle growth, Geophys. Res. Lett., 35, L04808, doi:10.1029/2007GL032523, 2008.

Smith, J. N., Barsanti, K. C., Friedli, H. R., Ehn, M., Kulmala, M., Collins, D. R., Scheckman, J. H., Williams, B. J., and McMurry, P. H.: Observations of aminium salts in atmospheric nanoparticles and possible climatic implications, P. Natl. Acad. Sci, 107, 6634-6639, 2010.

Sogacheva, L., Dal Maso, M., Kerminen, V.-M., and Kulmala, M.: Probability of nucleation events and aerosol particle concentration in different air mass types arriving at Hyytiälä, southern Finland, based on back trajectories analysis, Boreal Environ. Res., 10, 479-491, 2005.

Stolzenburg, M. R.: An Ultrafine Aerosol Size Distribution Measuring System, Ph.D. Thesis, Department of Mechanical Engineering, University of Minnesota, Minneapolis, MN, USA, 1988.

Stolzenburg, M. R. and McMurry, P. H.: An Ultrafine Aerosol Condensation Nucleus Counter, Aerosol Sci. Tech., 14, 48-65, 1991.

Stolzenburg, M. R. and McMurry, P. H.: Equations governing single and tandem DMA configurations and a new lognormal approximation to the transfer function, Aerosol Sci. Tech., 42, 421-432, 2008.

Stolzenburg, M. R., McMurry, P. H., Sakurai, H., Smith, J. N.,
Mauldin III, R. L., Eisele, F. L., and Clement, C. F.: Growth rates of freshly nucleated particles in Atlanta, J. Geophys. Res., 110, D22S05, doi:10.1029/2005JD005935, 2005.

Suni, T., Kulmala, M., Hirsikko, A., Bergman, T., Laakso, L., Aalto, P. P., Leuning, R., Cleugh, H., Zegelin, S., Hughes, D., van Gorsel, E., Kitchen, M., Vana, M., Hõrrak, U., Mirme, A., Sevanto, S., Twining, J., and Tadros, C.: Formation and characteristics of ions and charged aerosol particles in a native Australian Eucalypt forest, Atmos. Chem. Phys., 8, 129-139, doi:10.5194/acp-8-129-2008, 2008.

Suni, T., Sogacheva, L., Lauros, J., Hakola, H., Bäck, J., Kurtén, T., Cleugh, H., van Gorsel, E., Briggs, P., Sevanto, S., and Kulmala, M.: Cold oceans enhance terrestrial new-particle formaton in near-coastal forests, Atmos. Chem. Phys., 9, 8639-8650, doi:10.5194/acp-9-8639-2009, 2009.

Suzuki, K., Iritani, M., and Mitsukuchi, T.: Measurements of small ion mobility spectrum with multi-electrodes Gerdien condenser, Res. Lett. Atmos. Electr., 2, 1-4, 1982.

Svenningsson, B., Arneth, A., Hayward, S., Holst, T., Massling, A., Swietlicki, E., Hirsikko, A., Junninen, H., Riipinen, I., Vana, M., Dal Maso, M., Hussein, T., and Kulmala, M.: Aerosol particle formation events and analysis of high growth rates observed above a subarctic wetland-forest mosaic, Tellus, 60B, 353-364, 2008.

Szegvary, T., Conen, F., Stöhlker, U., Dubois, G., Bossew, P., and de Vries, G.: Mapping terrestrial $\gamma$-dose rate in Europe based on routine monitoring data, Radiat. Meas., 42, 1561-1572, 2007.

Szegvary, T., Conen, F., and Ciais, P.: European ${ }^{222}$ Rn inventory for applied atmospheric studies, Atmos. Environ., 43, 1536-1539, 2009.

Tammet, H.: The aspiration method for the determination of atmospheric ion-spectra, Israel Program for Scientific Translations, Jerusalem, 208 pp., 1970.

Tammet, H.: Size and mobility of nanometer particles, clusters and ions, J. Aerosol Sci., 26, 459-475, 1995.

Tammet, H.: Reduction of air ion mobility to standard conditions, J. Geophys. Res., 103, 13933-13937, 1998.

Tammet, H.: The limits of air ion mobility resolution, Proc. 11th Int Conf. Atmos. Electr., NASA, MSFC, Alabama, 626-629, 1999.

Tammet, H.: Inclined grid mobility analyzer: The plain model, Abstracts of Sixth International Aerosol Conference, International Aerosol Research Assembly, Taipei, 2, 647-648, 2002.

Tammet, H.: Method of inclined velocities in the air ion mobility analysis, in: Proceedings of the 12-th International Conference on Atmospheric Electricity, International Commision on Atmospheric Electricity, Versailles, 1, 399-402, 2003.

Tammet, H.: Continuous scanning of the mobility and size distribution of charged clusters and nanoparticles in atmospheric air and the Balanced Scanning Mobility Analyzer BSMA, Atmos. Res. 82, 523-535, 2006.

Tammet, H.: A joint dataset of fair-weather atmospheric electricity, Atmos. Res., 91, 194-200, http://dx.doi.org/doi:10.1016/j. atmosres.2008.01.012, 2009.

Tammet, H. F., Jakobson, A. F., and Salm, J. J.: Multi-channel automatic air ion spectrometer (in Russian), Acta Comm. Univ. Tartu., 320, 48-75, 1973.

Tammet, H., Hõrrak, U., Laakso, L., and Kulmala, M.: Factors of air ion balance in a coniferous forest according to measurements in Hyytiälä, Finland, Atmos. Chem. Phys., 6, 3377-3390, 
doi:10.5194/acp-6-3377-2006, 2006.

Tammet, H., Hõrrak, U., and Kulmala, M.: Negatively charged nanoparticles produced by splashing of water, Atmos. Chem. Phys., 9, 357-367, doi:10.5194/acp-9-357-2009, 2009.

Thomson, J. J.: Conduction of Electricity through Gases, Cambridge University Press, Cambridge, Vi, 566 pp., 1903.

Tiitta, P., Miettinen, P., Vaattovaara, P., Laaksonen, A., Joutsensaari, J., Hirsikko, A., Aalto, P. and Kulmala, M.: Road-side measurements of aerosol and ion number size distributions: a comparison with remote site measurements, Boreal Environ. Res., 12, 311321, 2007.

Tuomi, T. J.: Ten year summary 1977-1986 of atmospheric electricity measured at Helsinki-Vantaa airport, Finland, Geophysica, $25,1-20,1989$

Vakkari, V., Laakso, H., Kulmala, M., Laaksonen, A., Mabaso, D., Molefe, M., Kgabi, N., and Laakso, L.: New particle formation events in semi-clean South African savannah, Atmos. Chem. Phys. Discuss., 10, 30777-30821, 2010,

http://www.atmos-chem-phys-discuss.net/10/30777/2010/

Vana, M., Kulmala, M., Dal Maso, M., Hõrrak, U., and Tamm, E.: Comparative study of nucleation mode aerosol particles and intermediate ions formation events at three sites, J. Geophys. Res., 109, D17201, doi:10.1029/2003JD004413, 2004.

Vana, M., Tamm, E., Hõrrak, U., Mirme, A., Tammet, H., Laakso, L., Aalto, P. P., and Kulmala, M.: Charging state of atmospheric nanoparticles during the nucleation burst events, Atmos. Res., 82, 536-546, 2006a.

Vana, M., Hirsikko, A., Tamm, E., Aalto, P., Kulmala, M., Verheggen, B., Cozic, J., Weingartner, E., and Baltensperger, U.: Characteristics of Air Ions and Aerosol Particles at the High Alpine Research Station Jungfraujoch, Proceedings of 7-th International Aerosol Conference, the American Association for Aerosol Research (AAAR), ISBN 978-0-9788735-0-9, 1427, 2006b.

Vana, M., Virkkula, A., Hirsikko, A., Aalto, P., Kulmala, M., and Hillamo, R.: Air Ion Measurements During a Cruise from Europe to Antarctica, Proceedings of Nucleation and Atmospheric Aerosols 17-th International Conference Galway, Ireland 2007, Springer, ISBN 978-1-4020-647-6, 368-372, 2007.

Vana, M., Ehn, M., Petäjä, T., Vuollekoski, H., Aalto, P., de Leeuw, G., Ceburnis, D., O'Dowd, C.D., and Kulmala, M.: Characteristic features of air ions at Mace Head on the west coast of Ireland, Atmos. Res., 90, 278-286, 2008.

Vanhanen, J., Mikkilä, J., Lehtipalo, K., Sipilä, M., Manninen, H. E., Siivola, E., Petäjä, T., and Kulmala, M.: Particle Size Magnifier for Nano-CN Detection, Aerosol Sci. Technol., 45, 4, 533542,2011

Vartiainen, E., Kulmala, M., Ehn, M., Hirsikko, A., Junninen, H., Petäjä, T., Sogacheva, L., Kuokka, S., Hillamo, R., Skorokhod, A., Belikov, I., Elansky, N., and Kerminen, V.-M.: Ion and particle number concentrations and size distributions along the TransSiberian railroad, Boreal Environ. Res., 12, 375-396, 2007.

Venzac, H., Sellegri, K., and Laj, P.: Nucleation events detected at the high altitude site of the Puy de Dôme Research Station, France, Boreal Environ. Res., 12, 345-359, 2007.

Venzac, H., Sellegri, K., Laj, P., Villani, P., Bonasoni, P., Marinoni, A., Cristofanelli, P., Calzolari, F., Fuzzi, S., Decesari, S., Facchini, M.-C., Vuillermoz, E., and Verza, G. P.: High frequency new particle formation in the Himalayas, P. Natl. Acad.
Sci. USA, 105, 15666-15671, 2008.

Viggiano, A. A.: In situ mass spectrometry and ion chemistry in the stratosphere and troposphere, Mass Spectrom. Rev., 12, 115137, 1993.

Virkkula, A., Hirsikko, A., Vana, M., Aalto, P. P., Hillamo, R., and Kulmala, M.: Charged particle size distributions and analysis of particle formation events at the Finnish Antarctic research station Aboa, Boreal Environ. Res., 12, 397-408, 2007.

Voisin, D., Smith, J. N., Sakurai, H., McMurry, P. H., and Eisele, F. L.: Thermal Desorption Chemical Ionization Mass Spectrometer for Ultrafine Particle Chemical Composition, Aerosol Sci. Tech., 37, 471-475, 2003.

Weber, R. J., Marti, P., McMurry, P. H., Eisele, F. L., Tanner, D. J., and Jefferson, A.: Measured atmospheric new particle formation rates: implications for nucleation mechanisms, Chem. Eng. Comm., 151, 53-64, 1996.

Weber, R. J., Marti, J. J., McMurry, P. H., Eisele, F. L., Tanner, D. J., and Jefferson, A.: Measurements of new particle formation and ultrafine particle growth rates at a clean continental site, J. Geophys. Res., 102, 4375-4385, 1997.

Weber, R. J., McMurry, P. H., Mauldin, L., Tanner, D. J., Eisele, F. L., Brechtel, F. J., Kreidenweis, S. M., Kok, G. L., Schillaswki, R. D., and Baumgardner, D.: A study of new particle formation and growth involving biogenic and trace gas species measured during ACE 1, J. Geophys. Res., 103, 16,385-16,396, 1998.

Weber, R. J., McMurry, P. H., Mauldin III, R. L., Tanner, D. J., Eisele, F. L., Clarke, A. D., and Kapustin, V. N.: New particle formation in the remote troposphere: A comparison of observations at various sites, Geophys. Res. Lett., 26(3), 307-310, 1999.

Wilding, R. J. and Harrison, R. G.: Aerosol modulation of small ion growth in coastal air, Atmos. Environ., 39, 5876-5883, 2005.

Winkler, P. M., Steiner, G., Vrtala, A., Vehkamäki, H., Noppel, M., Lehtinen, K. E. J., Reischl, G. P., Wagner, P. E., and Kulmala, M.: Heterogenous Nucleation Experiments Bridging the Scale form Molecular Ion Cluster to Nanoparticles, Science, 7, 1374-1377, 2008.

Yli-Juuti, T., Riipinen, I., Aalto, P. P. Nieminen, T., Maenhaut, W., Janssens, I. A., Clayas , S. I., Ocskay, R., Hoffer, A., Imre, K., and Kulmala M.: Characteristics of new particle formation events and cluster ions at K-puszta, Hungary, Boreal Environ. Res., 14, 683-698, 2009.

Yu, F.: Ion-mediated nucleation in the atmosphere: Key controlling parameters, implications, and look-up table, J. Geophys. Res., 115, D03206, doi:10.1029/2009JD012630, 2010.

Yu, F. and Turco, R. P.: Ultrafine aerosol formation via ionmediated nucleation, Geophys. Res. Lett., 27, 883-886, 2000.

Yu, F. and Turco, R.: Case studies of particle formation events observed in boreal forests: implications for nucleation mechanisms, Atmos. Chem. Phys., 8, 6085-6102, doi:10.5194/acp-86085-2008, 2008.

Yu, F., Luo, G., Bates, T. S., Andersson, B., Clarke, A., Kapustin, V., Yantosca, R. M., Wang, Y., and Wu, S.: Spatial distributions of particle number concentrations in the global troposphere: Simulations, observations, and implications for nucleation mechanism, J. Geophys. Res., 115, D17205, doi:10.1029/2009JD013473, 2010.

Yunker, E. A.: The mobility spectrum of atmospheric ions, Terr. Magn. Atmos. Electr., 45, 127-132, 1940.

Zeleny, J.: On the ratio of velocities of the two ions produced in 
gases by Röngten radiation, and on some related phenomena, Philos. Mag., 46, 120-154, 1898.

Zeleny, J.: The velocity of ions produced in gases by Röntgen rays, Philos. Trans. Roy. Soc. A, 195, 193-234, 1900.

Zhang, S.-H., Akutsu, Y., Russell, L. M., Flagan, R. C., and Seinfeld, J. H.: Radial differential mobility analyzer, Aerosol Sci. Techn., 23, 357-72, 1995.
Zhao, J., Eisele, F. L., Titcombe, M., Kuang, C., and McMurry, P. H.: Chemical Ionization Mass Spectrometric Measurements of Atmospheric Neutral Clusters using the Cluster-CIMS, J. Geophys. Res., 115, D08205. doi:10.1029/2009JD012606, 2010.

Zwang, L. R. and Komarov, N. N.: A study of small ion spectra in the free atmosphere, Izv. Acad. Sci. USSR, Geophys. Series, 1167-1176, 1959. 